\title{
Harmonic Perception and Voice Leading Spaces of Set Classes Related by Unordered Interval Classes
}

\author{
Percepção Harmônica e Espaços Parcimoniosos em Classes de Conjuntos \\ Relacionadas por Classes de Intervalos Não-Ordenados ${ }^{1}$
}

\section{Rodolfo Coelho de Souza \\ University of São Paulo}

\begin{abstract}
We call PCORD the prime form the interval string of Forte's set classes. Analysis based on PCORD relations can yield a structural similarity between two different set classes, besides some possible perceptual likeness, measured by trichordal content. However different, the PCORD relation is analog to Forte's Z-relation, but more embracing. This study provides the table of all set classes related by PCORD to be used as an analytical and compositional tool. The paper points out a precursor analytical use of the PCORD relation by Richard Parks in Debussy's music. To demonstrate the analytical application of PCORDrelations, we analyzed four excerpts: from Hans Otte's Das Buch der Klänge (1982), VillaLobos' Rudepoema (1920) and from Coelho de Souza's Metropolis (1990) and Dialogues (1987). We also analyzed the harmonic content of set classes using trichords or PCORDs of cardinality 3 and the PCORD connections in the voice-leading space of set classes with cardinality 3 to 9 . Finally, we proposed that PCORD theory can be used as a compositional tool to engender harmonic directionality in atonal progressions.
\end{abstract}

Keywords: Z-relation; set class similarity; voice-leading space; set class perception; atonal progressions.

Resumo: Chamamos PCORD a forma primária da cadeia de intervalos das classes de conjuntos de Forte. Análises baseadas em relações PCORD podem revelar similaridades estruturais entre diferentes classes de conjuntos, além de possíveis semelhanças perceptivas que podem ser medidas através do conteúdo de tricordes. Apesar de diferentes, relações por PCORD são similares às relações $Z$, porém mais abrangentes. Este estudo fornece a tabela de todas as classes de conjuntos relacionadas por PCORD para serem usadas como ferramentas analíticas e composicionais. O artigo aponta um uso precursor da relação PCORD por Parks na análise da música de Debussy. Para demonstrar a aplicação analítica das relações PCORD, analisamos quatro excertos: de Hans Otte, Das Buch der Klänge (1982), de Villa-Lobos,

${ }^{1}$ A short version of this paper was presented at the Symposium Música Analitica 2019 held at Catholic University of Porto, Portugal. 
MUSICA THEORICA Revista da Associação Brasileira de Teoria e Análise Musical 2018, v. 3, n. 2, p. 46-85 - Journal of the Brazilian Society for Music Theory and Analysis @ TeMA 2018 - ISSN 2525-5541

Rudepoema (1920) e de Coelho de Souza, Metropolis (1990) e Diálogos (1987). Analisamos também o conteúdo harmônico das classes de conjunto usando PCORDs de cardinalidade 3 e as conexões PCORD no espaço de condução parcimoniosa de vozes em classes de conjuntos com cardinalidade 3 a 9. Finalmente propomos que a teoria de PCORDs pode ser usada como uma ferramenta composicional para engendrar direcionalidade harmônica em progressões atonais.

Palavras-chave: Relação Z; similaridade de classes de conjuntos; espaços parcimoniosos de condução de voz; percepção de classes de conjuntos; progressões atonais.

\section{A classical problem}

Suppose we want to analyze the excerpt of Santoro's Piano Sonata 1942 displayed in Example 1.

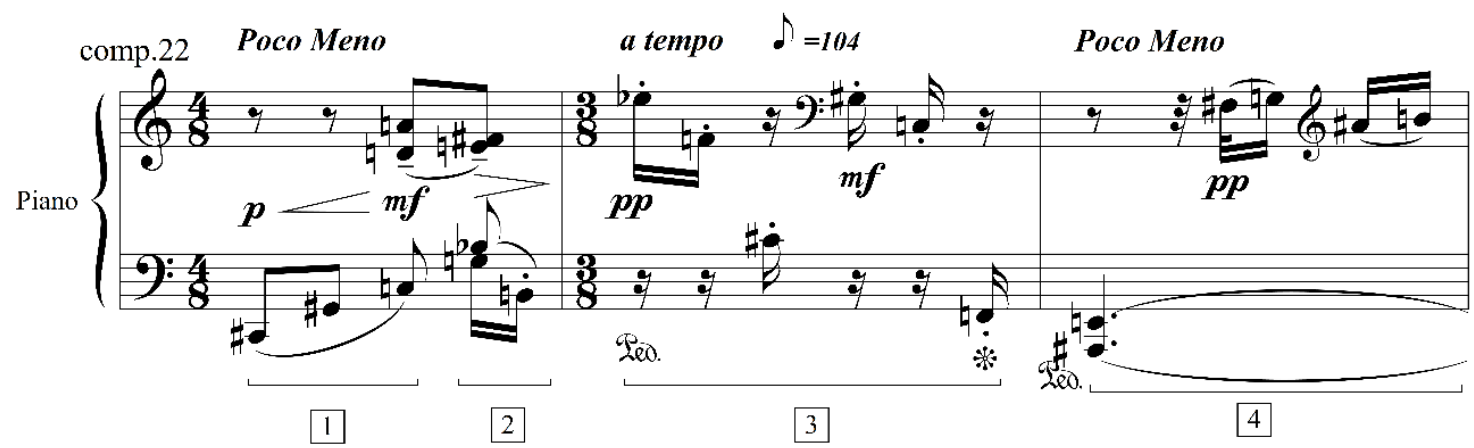

Example 1: Excerpt of Santoro's Piano Sonata $1942 \mathrm{~mm}$. 22-25 with segmentation

After a superficial inspection, we might guess that this passage emphasizes sets of five pitches. Barlines suggest this segmentation. Following, we reduced pitch-class sets to set classes, in order to look for some relation between them.

$\begin{array}{lllll}\text { Sets: } & 1 & 2 & 3 & 4 \\ & \{\mathrm{C} \#, \mathrm{G} \#, \mathrm{C}, \mathrm{D}, \mathrm{A}\} & \{\mathrm{G}, \mathrm{Bb}, \mathrm{E}, \mathrm{F} \#, \mathrm{~B}\} & \{\mathrm{Eb}, \mathrm{F}, \mathrm{C} \#, \mathrm{G} \#, \mathrm{C}\} & \{\mathrm{A} \#, \mathrm{E}, \mathrm{F} \#, \mathrm{G}, \mathrm{B}\} \\ & \{0,1,2,8,9\} & \{4,6,7, \mathrm{~T}, \mathrm{E}\} & \{0,1,3,5,8\} & \{4,6,7,9,11\} \\ \text { Set Class: } & 5-6(01256) & 5-\mathrm{Z18}(01457) & 5-27(01358) & 5-23(02357)\end{array}$

Figure 1: Set classes of the segmentation of Santoro's Sonata 1942, mm. 22-25

What did we find? Absolutely nothing. We found that the four sets belong to different set classes and this hardly means something. This happens all the time. Most of the time when we try to analyze music with set theory, seldom we reach immediately some consistent set class relation.

Maybe the ideal analytical finding would be that all sets belong to the same set class. This certainly would imply the piece has a strong coherence. We 
might also be glad to find that the piece uses a limited number of set classes. This might mean that there is contrast between sets but still some coherence. But, when we find many different set classes, as we did, can we make sense of some relation between them? Is there, perhaps, some common link other than the already mentioned usual analytical paradigms? Or, is there some logic in this atonal set class progression?

The complexity of the problem made Hanninen remark that

used in conjunction with criteria for segmentation and perhaps a theory of musical structure or syntax chosen by the analyst (such as Schenkerian theory of twelve-tone theory), this general [segmentation] theory of analysis can illuminate workings of and interactions among sonic, contextual, and structural aspects of music, at multiple levels of conceptualization and organization" (Hanninen 2012, p. 4).

\section{The PCORD relation}

We have proposed the PCORD relation, ${ }^{2}$ concerning set classes, as follows: Consider the segment $A=\{E, D, F \sharp A, G\}=\{3,2,6,9,7\}$. This pitch-set has the interval string: [1 $\left.4 \begin{array}{lll}1 & 3 & 2\end{array}\right]$.

Soderberg (1995, p. 80) defined CORD (A) as the "compact circular ordering" of the intervals of A. Soderderg (1995, p. 100) also reminded us that “the CORD is related to Robert Morris' 'interval succession' (Morris 1987) and has roots stretching back at least as far as Howard Hanson's 'intervallic order' (Hanson 1960). CORD is obviously a step on the way to determining the 'normal order' or 'prime form' of a set". We may also notice its similarity to the vector BIP (basic interval pattern) defined and applied by Allen Forte (1973) to problems of set identity and similarity. Forte notices also that the interval succession of the prime form does not necessarily coincides with the interval succession of the original set, as this example demonstrates.

Rearranging set-A in normal form we have: $\{2,3,6,7,9\}$

Making the proper calculation, we find its prime form: (0 1457 )

The CORD of the prime form of $\mathrm{A}$, noted with double square brackets as proposed by Soderberg (1995, p. 80) is:

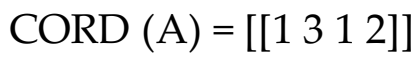

\footnotetext{
${ }^{2}$ The definition of the PCORD relation was originally proposed in Coelho de Souza, 2012.
} 
MUSICA THEORICA Revista da Associação Brasileira de Teoria e Análise Musical 2018, v. 3, n. 2, p. 46-85 - Journal of the Brazilian Society for Music Theory and Analysis@ TeMA 2018 - ISSN 2525-5541

We defined PCORD (A) as the prime (or normal) $)^{3}$ form of CORD, noted with double parenthesis:

$\operatorname{PCORD}(\mathrm{A})=((1123))$

PCORDs are, therefore, set classes formed by the unordered interval strings of set classes. All set classes, whose prime form may be generated by the reordering the intervals of a PCORD vector, belong to the same PCORD class. Therefore, a PCORD can be considered both a class and a vector.

This paper proposes some applications of PCORD, including a taxonomy of Forte's set classes based, their similarity properties, and the study of voice leading spaces leading to the perception of set classes harmonic progressions.

Finally, we must notice that the BIP vector is different from PCORD because the former can be applied to any set, while the later, just to prime forms of set classes. Forte's goal was to count how many different BIPs could be derived from a pc set class. He comments that "the main point is that the number as well the types of bips is not an obvious property of the total interval content of a pc set, but is determined by the pc structure of the set as it imposes restrictions on the formation of linear intervallic successions" (Forte 1973, p. 69). To demonstrate it, he proceeds providing a table of counts of basic interval patterns for pc sets of cardinality 4 to 6 . However, at any moment, Forte considers the BIP of a pc set class as particularly significant.

On the other hand, we find in Parks (1989) a precursor usage of the BIP vector to characterize a relation between set classes, which ultimately constitutes an application of the concept of unordered interval string to set classes. In the chapter 3 of his book on Debussy's music, using Forte's set theory, Parks proposes a theory of set genera. In that chapter, Parks actually does not raise explicitly the question of interval succession applied to set classes. However, on his Table 4.1 (Parks 1989, p. 107) of chapter 4, when considering the application of his $4^{\text {th }}$ genera ("8-17/18/19-Complex") to Debussy's early works, Parks shows, in the last column, the identity of the interval strings of these set classes (Figure 2). Even though his text does not emphasize this occurrence, he was offering,

\footnotetext{
${ }^{3}$ It may be argued that it would be more precise to say, "the normal form of a CORD set". However, in this case, the normal and prime forms have the same expression. As Forte (1973, p. 64) explains, the BIP is "merely a normalization of the interval succession". We wanted to assert the more general status of PCORD as a prime form. Anyway, there is no need to go into this hairsplitting problem. Ultimately, it does not make any difference.
} 
implicitly, this particular identity as the motive for grouping the set classes under the same genus. It is precisely this point that we aim in this study: to generalize to all set classes the principle raised by Parks in that specific case.

\begin{tabular}{lccc}
\hline \multicolumn{1}{c}{ Genus } & Set & SIA & BIP \\
\hline 8-17/18/19-Complex & $8-17(01345689)$ & $1-2-1-1-1-2-1-3$ & 11111223 \\
& $8-18(01235689)$ & $1-1-1-2-1-2-1-3$ & 11111223 \\
& $8-19(01245689)$ & $1-1-2-1-1-2-1-3$ & 11111223 \\
\hline Diatonic & $8-22(0123568 \mathrm{~T})$ & $1-1-1-2-1-2-2-2$ & 11112222 \\
& $8-23(0123578 \mathrm{~T})$ & $1-1-1-2-2-1-2-2$ & 11112222 \\
& $8-26(0134578 \mathrm{~T})$ & $1-1-2-1-2-2-1-2$ & 11112222 \\
\hline Whole-tone & $8-21(0123468 \mathrm{~T})$ & $1-1-1-1-2-2-2-2$ & 11112222 \\
& $8-24(0124568 \mathrm{~T})$ & $1-1-2-1-1-2-2-2$ & 11112222 \\
\hline Octatonic & $8-25(0124678 \mathrm{~T})$ & $1-1-2-2-1-1-2-2$ & 11112222 \\
\hline
\end{tabular}

Figure 2: SIAs e BIPs for octachords from the 8-17/18/19-complex, diatonic, whole-tone, and octatonic pc set genera (adapted from Table 4.1 in Parks 1989, p. 107)

Besides Parks, we have mentioned Soderberg's definition of CORD (1995, p. 100), which concerns a study of the interval succession applied to the Zrelation. Our research has some parallelisms with Soderberg's, insofar both are devoted to the problem of interval strings. Soderberg proved that the Z-relation is the result of a "dual inversion" of set elements. ${ }^{4}$

Therefore, we might consider useful to make clear the distinction between PCORD and Z-relations.

\section{The Z-relation}

To start, it is convenient to review the definition of Z-relation to compare it with the PCORD-relation.

Allen Forte's Z-relation (1973, p. 21) also concerns the problem of finding set classes relations. It acknowledges a particular relation between certain set classes, inasmuch they share the same absolute interval-class vector (APIC).

\footnotetext{
${ }^{4}$ Soderberg extends the concept of simple inversion to a relation he refers to as dual inversion: "under [certain] circumstances ..., if some of the elements of $A$ invert with respect to index $x$ while the other elements of $A$ invert with respect to index $y$, the resulting set $B$ may be neither a simple transposition nor a simple inversion of $\mathrm{A}$, but both sets may nonetheless share the same interval-class vector; that is, A and B may be Z-related" (Soderberg 1995, p. 77).
} 
The APIC vector aims to measure the intervallic content of a PC set, counting the frequency of occurrences of the intervals between all members of the set, leaving out unison pairs because this information is redundant.

Every set that belongs to a set class has the same APIC vector, but the reciprocal is not true. Not every set that has the same APIC vector belongs to the same set class. By the way, Forte (1964) initially hypothesized that APIC vectors might be used to define set classes. Soon he realized the problem with the reciprocal property. Instead, he recognized this kind of occurrence as a particular structural similarity between pairs of sets and set classes, calling it a Z-relation.

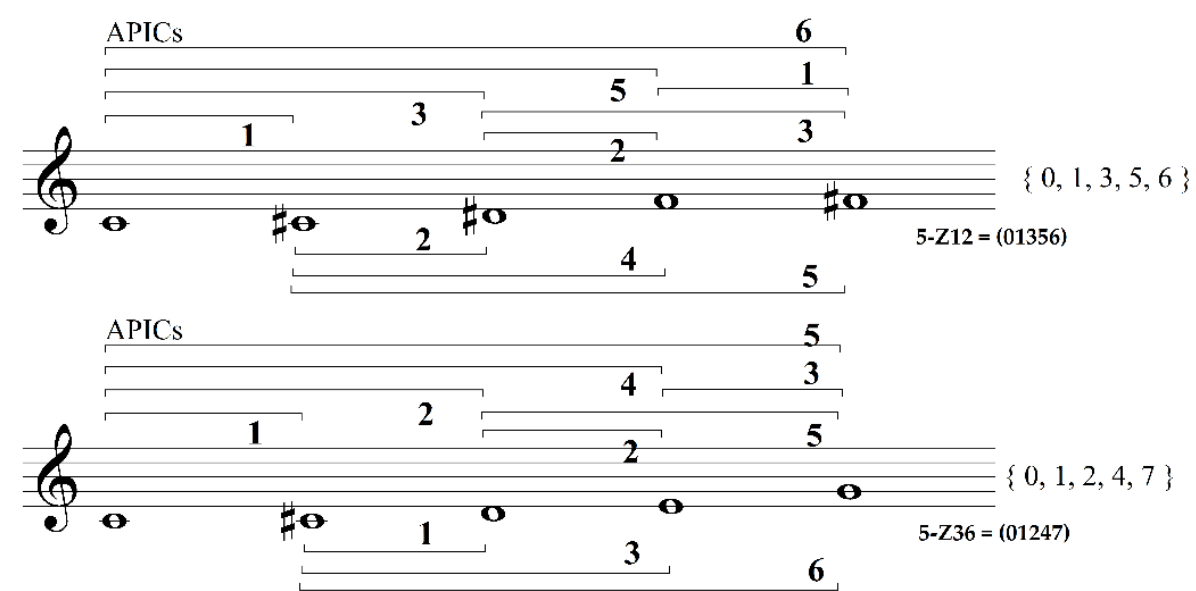

\begin{tabular}{|c|c|c|c|c|c|c|c|c|c|c|c|}
\hline APIC matrix: & & 0 & 1 & 3 & 5 & 6 & & 0 & 1 & 2 & 4 \\
\hline & 0 & 0 & 1 & 3 & 5 & 6 & 0 & 0 & 1 & 2 & 4 \\
\hline & 1 & & 0 & 2 & 4 & 5 & 1 & & 0 & 1 & 3 \\
\hline & 3 & & & 0 & 2 & 3 & 2 & & & 0 & 2 \\
\hline & 5 & & & & 0 & 1 & 4 & & & & 0 \\
\hline & 6 & & & & & 0 & 7 & & & & \\
\hline Interval-class: & 1 & 2 & 3 & 4 & 5 & 6 & 1 & 2 & 3 & 4 & 5 \\
\hline APICs & 2 & 2 & 2 & 1 & 2 & 1 & 2 & 2 & 2 & 1 & 2 \\
\hline
\end{tabular}

Figure 3: In a Z-relation, the APIC vector is the same for two different sets

Figure 3 plots the interval-class counting of two different sets, resulting in the same APIC vector. Therefore, set classes (01356) and (01247) are Z related.

However, from the 208 set classes (of cardinality 3 to 9), only 52 (25\%) belong to a Z-pair. Moreover, Z-related sets exist in pairs and in pairs only. There are not large families of Z-related sets, as it can occur with PCORD related sets. We will see that $90 \%$ of set classes have at least one PCORD correspondent and 
many have multiple correspondents. Therefore, at least in terms of probability, there is a better chance of finding examples of the use of PCORD-relations than of Z-relations. This was the initial encouragement for our research.

\section{PCORD and Z-relation}

In a previous presentation of an earlier stage of this research, a question was raised objecting that we might be elaborating a concept equivalent to the $Z$ relation. Instead of providing a rigorous proof that PCORD-relations and Zrelations are different concepts, we think that it is enough to show examples demonstrating that these concepts do not superimpose.

Consider, for instance, two set classes $\mathrm{A}$ and $\mathrm{B}$ that are $\mathrm{Z}$ related because their APIC vectors [212320] are the same according to Forte's set class table. They have, respectively, the following PCORD vectors:

$$
\begin{aligned}
& \mathrm{A}=5 \mathrm{Z}-17(01348) \rightarrow \mathrm{APIC}=212320 \rightarrow \mathrm{CORD}=[[1214]] \rightarrow \mathrm{PCORD}(\mathrm{A})=((1124)) \\
& \mathrm{B}=5 \mathrm{Z}-37(03458) \rightarrow \mathrm{APIC}=212320 \rightarrow \mathrm{CORD}=[[3113]] \rightarrow \mathrm{PCORD}(\mathrm{B})=((1133))
\end{aligned}
$$

Therefore, $\mathrm{A}$ and $\mathrm{B}$ are Z-related but do not have the same PCORD vector.

On the other hand, we may have two set classes that are PCORD related but not Z-related. For instance:

$$
\begin{aligned}
& C=5-14(01257) \rightarrow \mathrm{CORD}=[[1132]] \rightarrow \mathrm{PCORD}(\mathrm{C})=((1123)) \rightarrow \mathrm{APIC}(\mathrm{C})=221131 \\
& \mathrm{D}=5-19(01367) \rightarrow \mathrm{CORD}=[[1231]] \rightarrow \mathrm{PCORD}(\mathrm{D})=((1123)) \rightarrow \mathrm{APIC}(\mathrm{D})=212122
\end{aligned}
$$

Therefore, C and D are PCORD-related but not Z-related.

In Set Theory, PCORD and Z-relation are $2^{\text {nd }}$ order relations. ${ }^{5}$ This means that they are relations concerned with another relation, the intervals, and not with primary elements, the pitch-classes.

PCORD is different from Z-relation, but there might exist pairs of set classes that share both properties. Oliveira (1998, p. 278) lists 46 type-Z set classes, which relate in 23 pairs. However, only $17 \%$ of them are simultaneously $Z$ and PCORD related. As listed below, they are three pairs of cardinality 6 and one pair of cardinality 8:

\footnotetext{
${ }^{5}$ Pitch relations, as intervals, constitute the first-order of set theory. Relations between intervals, as $\mathrm{Z}$ and PCORD-relations, belong to a second-order level. We can compare with Mechanics: the concept of spatial position in time is a first-order relation; speed, a second-order, and acceleration, a third-order. Every time we go up one order, the level of abstraction increases. We perceive these variable relations of speed and acceleration as if they were interval changes.
} 


$$
\begin{aligned}
& 6 \mathrm{Z}-17(012478) \rightarrow \mathrm{PCORD}=((11123)) \rightarrow \mathrm{APIC}=322332 \\
& 6 \mathrm{Z}-43(012568) \rightarrow \mathrm{PCORD}=((11123)) \rightarrow \mathrm{APIC}=322332 \\
& 6 \mathrm{Z}-28(013569) \rightarrow \mathrm{PCORD}=((11223)) \rightarrow \mathrm{APIC}=224322 \\
& 6 \mathrm{Z}-49(013479) \rightarrow \mathrm{PCORD}=((11223)) \rightarrow \mathrm{APIC}=224322 \\
& 6 \mathrm{Z}-29(023679) \rightarrow \mathrm{PCORD}=((11123)) \rightarrow \mathrm{APIC}=224232 \\
& 6 \mathrm{Z}-50(014679) \rightarrow \mathrm{PCORD}=((11123)) \rightarrow \mathrm{APIC}=224232 \\
& 8 \mathrm{Z}-15(01234689) \rightarrow \mathrm{PCORD}=((1111122)) \rightarrow \mathrm{APIC}=555553 \\
& 8 \mathrm{Z}-29(01235679) \rightarrow \mathrm{PCORD}=((1111122)) \rightarrow \mathrm{APIC}=555553
\end{aligned}
$$

\section{PCORD, set complex, and set similarity}

Set Complex and Set Similarity, besides the Z-relation, were other means proposed by Forte (1973) to deal with the problem of relating sets which do not reveal some identity after isomorphic transformations (transposition, inversion, etc.) or equivalence of interval vectors. Set complexes deal with formal operations of inclusion, sub-sets, super-sets, and complements. They are indeed adequate tools because they follow a strict formal logic and can justify why a passage of atonal music sounds structurally convincing. They also have the advantage of being capable of dealing with sets of different cardinalities.

On the other hand, the problem of similarity departs from a different standpoint. Schuijer (2008) gives us a detailed account of the evolution of different theoretical approaches to this topic. The initial propositions, by Forte (1973) and Lord (1981), dealt with sets of the same cardinality by comparing their interval vectors. Following them, Morris (1979), Rahn (1979, 1989), Lewin (1959, 1960, 1977 and 1979) and Isaacson (1990) expanded the topic to sets of different cardinalities but also had the interval vectors as the reference for comparisons. Their goal was to obtain a numerical measurement of an index of similarity.

PCORD relations are a matter of similarity, even though it does not yield a numerical formula for measurement of similarities. More likely, it may be seen as an isomorphic operation, because PCORD shuffles the interval ordering, but keeps the same generative intervals. Therefore, PCORD maps the intervals of one set into another as a transformational vector. The concept of mapping seems quite adequate to describe the status of this relation.

On the other hand, the effects on perception are not immediately evident. We need to study first other structural properties of the PCORD relation. 


\section{A general taxonomy of set classes $x$ PCORD relations}

The following tables relate all 66 PCORDs with 208 set classes (for cardinalities 3 to 9): 12 of cardinality 3,15 of cardinality 4,13 of cardinality 5,11 of cardinality 6,7 of cardinality 7, 5 of cardinality 8 , and 3 of cardinality $9 .{ }^{6}$ For a computer generation model of all possible pitch-sets, an algorithm that sorts the intervals of these 66 PCORDs and performs systematic redundancy checks is more efficient and elegant than other using a model of direct pitch permutation, to generate all sets that belong to the 208 set classes.

\section{Cardinality 3:}

\begin{tabular}{|c|c|c|c|c|c|c|}
\hline PCORD & $\mathbf{( ( 1 1 ) )}$ & $\mathbf{( ( 1 2 ) )}$ & $\mathbf{( ( 1 3 ) )}$ & $\mathbf{( ( 1 4 ) )}$ & $\mathbf{( ( 1 5 ) )}$ & $\mathbf{( ( 2 2 ) )}$ \\
\hline Set Class & $3-1(012)$ & $3-2(013)$ & $3-3(014)$ & $3-4(015)$ & $3-5(016)$ & $3-6(024)$ \\
\hline
\end{tabular}

\begin{tabular}{|c|c|c|c|c|c|}
\hline $\mathbf{( ( 2 3 ) )}$ & $\mathbf{( ( 2 4 ) )}$ & $\mathbf{( ( 2 5 ) )}$ & $\mathbf{( ( 3 3 ) )}$ & $\mathbf{( ( 3 4 ) )}$ & $\mathbf{( ( 4 4 ) )}$ \\
\hline $3-7(025)$ & $3-8(026)$ & $3-9(027)$ & $3-10(036)$ & $3-11(037)$ & $3-12(048)$ \\
\hline
\end{tabular}

\section{Cardinality 4:}

\begin{tabular}{|c|c|c|c|c|c|c|}
\hline PCORD & $\mathbf{( ( 1 1 1 ) )}$ & $\mathbf{( ( 1 1 2 ) )}$ & $\mathbf{( ( 1 1 3 ) )}$ & $\mathbf{( ( 1 1 4 ) )}$ & $\mathbf{( ( 1 1 5 ) )}$ & $\mathbf{( ( 1 2 2 ) )}$ \\
\hline Set Class & $4-1(0123)$ & $4-2(0124)$ & $4-4(0125)$ & $4-5(0126)$ & $4-6(0127)$ & $4-11(0135)$ \\
& & $4-3(0134)$ & $4-7(0145)$ & $4-8(0156)$ & $4-9(0167)$ & $4-10(0235)$ \\
\hline
\end{tabular}

\begin{tabular}{|c|c|c|c|c|c|}
\hline $\mathbf{( ( 1 2 3 ) )}$ & $\mathbf{( ( 1 2 4 ) )}$ & $\mathbf{( ( 1 3 3 ) )}$ & $\mathbf{( ( 1 3 4 ) )}$ & $\mathbf{( ( 2 2 2 ) )}$ & $\mathbf{( ( 2 2 3 ) )}$ \\
\hline $4-13(0136)$ & $4-Z 29(0137)$ & $4-18(0147)$ & $4-19(0148)$ & $4-21(0246)$ & $4-22(0247)$ \\
$4-Z 15(0146)$ & $4-14(0237)$ & $4-17(0347)$ & $4-20(0158)$ & & $4-23(0257)$ \\
$4-12(0236)$ & $4-16(0157)$ & & & & \\
\hline
\end{tabular}

\begin{tabular}{|c|c|c|}
\hline $\mathbf{( ( 2 2 4 ) )}$ & $\mathbf{( ( 2 3 3 ) )}$ & $\mathbf{( ( 3 3 3 ) )}$ \\
\hline $4-24(0248)$ & $4-27(0258)$ & $4-28(0369)$ \\
$4-25(0268)$ & $4-26(0358)$ & \\
\hline
\end{tabular}

\footnotetext{
${ }^{6}$ These tables were part of Coelho de Souza 2012. Unfortunately, that publication had many mistakes, requiring that the correct tables were reprinted here.
} 
MUSICA THEORICA Revista da Associação Brasileira de Teoria e Análise Musical 2018, v. 3, n. 2, p. 46-85 - Journal of the Brazilian Society for Music Theory and Analysis@ TeMA 2018 - ISSN 2525-5541

Cardinality 5:

\begin{tabular}{|c|c|c|c|c|c|}
\hline PCORD & $\mathbf{( ( 1 1 1 1 ) )}$ & $\mathbf{( ( 1 1 1 2 ) )}$ & $\mathbf{( ( 1 1 1 3 ) )}$ & $\mathbf{( ( 1 1 1 4 ) )}$ & $\mathbf{( ( 1 1 2 2 ) )}$ \\
\hline Set Class & $5-1(01234)$ & $5-2(01235)$ & $5-4(01236)$ & $5-5(01237)$ & $5-9(01246)$ \\
& & $5-3(01245)$ & $5-6(01256)$ & $5-7(01267)$ & $5-10(01346)$ \\
& & & & & $5-Z 12(01356)$ \\
& & & & & $5-8(02346)$ \\
\hline
\end{tabular}

\begin{tabular}{|c|c|c|c|c|c|}
\hline $\mathbf{( ( 1 1 2 3 ) )}$ & $\mathbf{( ( 1 1 2 4 ) )}$ & $\mathbf{( ( 1 1 3 3 ) )}$ & $\mathbf{( ( 1 2 2 2 ) )}$ & $\mathbf{( ( 1 2 2 3 ) )}$ & $\mathbf{( ( 1 2 3 3 ) )}$ \\
\hline $5-Z 36(01247)$ & $5-13(01248)$ & $5-Z 38(01258)$ & $5-24(01357)$ & $5-27(01358)$ & $5-31(01369)$ \\
$5-14(01257)$ & $5-15(01268)$ & $5-21(01458)$ & $5-23(02357)$ & $5-29(01368)$ & $5-32(01469)$ \\
$5-16(01347)$ & $5-Z 17(01348)$ & $5-22(01478)$ & & $5-30(01468)$ & \\
$5-19(01367)$ & $5-20(01568)$ & $5-Z 37(03458)$ & & $5-25(02358)$ & \\
$5-Z 18(01457)$ & & & & $5-28(02368)$ & \\
$5-11(02347)$ & & & & $5-26(02458)$ & \\
\hline
\end{tabular}

\begin{tabular}{|c|c|}
\hline $\mathbf{( ( 2 2 2 2 ) )}$ & $\mathbf{( ( 2 2 2 3 ) )}$ \\
\hline $5-33(02468)$ & $5-34(02469)$ \\
& $5-35(02479)$ \\
\hline
\end{tabular}

Cardinality 6:

\begin{tabular}{|c|c|c|c|c|}
\hline PCORD & $\mathbf{( ( 1 1 1 1 1 ) )}$ & $\mathbf{( ( 1 1 1 1 2 ) )}$ & $\mathbf{( ( 1 1 1 1 3 ) )}$ & $\mathbf{( ( 1 1 1 1 4 ) )}$ \\
\hline Set Class & $6-1(12345)$ & $6-2(012346)$ & $6-Z 36(012347)$ & $6-Z 37(012348)$ \\
& & $6-Z 3(012356)$ & $6-5(012367)$ & $6-Z 38(012378)$ \\
& & $6-Z 4(012456)$ & $6-Z 6(012567)$ & $6-7(012678)$ \\
\hline
\end{tabular}

\begin{tabular}{|c|c|c|c|c|}
\hline $\mathbf{( ( 1 1 1 2 2 ) )}$ & $\mathbf{( ( 1 1 1 2 3 ) )}$ & $\mathbf{( ( 1 1 1 3 3 ) )}$ & $\mathbf{( ( 1 1 2 2 2 ) )}$ & $\mathbf{( ( 1 1 2 2 3 ) )}$ \\
\hline $6-9(012357)$ & $6-Z 40(012358)$ & $6-Z 42(012369)$ & $6-22(012468)$ & $6-Z 46(012469)$ \\
$6-Z 11(012457)$ & $6-Z 41(012368)$ & $6-Z 44(012569)$ & $6-Z 24(013468)$ & $6-Z 47(012479)$ \\
$6-Z 12(012467)$ & $6-15(012458)$ & $6-20(014589)$ & $6-Z 25(013568)$ & $6-Z 48(012579)$ \\
$6-Z 10(013457)$ & $6-Z 17(012478)$ & & $6-Z 26(013578)$ & $6-27(013469)$ \\
$6-Z 13(013467)$ & $6-Z 43(012568)$ & & $6-21(023468)$ & $6-Z 49(013479)$ \\
$6-8(023457)$ & $6-18(012578)$ & & $6-Z 23(023568)$ & $6-Z 28(013569)$ \\
& $6-14(013458)$ & & & $6-30(013679)$ \\
& $6-Z 19(013478)$ & & $6-31(014579)$ \\
& $6-16(014568)$ & & & $6-Z 50(014679)$ \\
& $6-Z 39(023458)$ & & $6-Z 45(023469)$ \\
& & & & $6-Z 29(023679)$ \\
\hline
\end{tabular}

\begin{tabular}{|c|c|}
\hline $\mathbf{( ( 1 2 2 2 2 ) )}$ & $\mathbf{( ( 2 2 2 2 2 ) )}$ \\
\hline 6-34 (013579) & 6-35(02468T) \\
6-33 (023579) & \\
6-32 (024579) & \\
\hline
\end{tabular}


Cardinality 7:

\begin{tabular}{|c|c|c|c|}
\hline PCORD & $\mathbf{( ( 1 1 1 1 1 1 ) )}$ & $\mathbf{( ( 1 1 1 1 1 2 ) )}$ & $\mathbf{( ( 1 1 1 1 1 3 ) )}$ \\
\hline Set Classes & $7-1(0123456)$ & $7-2(0123457)$ & $7-3(0123458)$ \\
& & $7-4(0123467)$ & $7-6(0123478)$ \\
& & $7-5(0123567)$ & $7-7(0123678)$ \\
\hline
\end{tabular}

\begin{tabular}{|c|c|c|c|}
\hline $\mathbf{( ( 1 1 1 1 2 2 ) )}$ & $\mathbf{( ( 1 1 1 1 2 3 ) )}$ & $\mathbf{( ( 1 1 1 2 2 2 ) )}$ & $\mathbf{( ( 1 1 2 2 2 2 ) )}$ \\
\hline $7-9(0123468)$ & $7-10(0123469)$ & $7-24(0123579)$ & $7-33(012468 \mathrm{~T})$ \\
$7-Z 36(0123568)$ & $7-Z 12(0123479)$ & $7-27(0124579)$ & $7-34(013468 \mathrm{~T})$ \\
$7-14(0123578)$ & $7-16(0123569)$ & $7-29(0124679)$ & $7-35(013568 \mathrm{~T})$ \\
$7-13(0124568)$ & $7-19(0123679)$ & $7-30(0124689)$ & \\
$7-Z 38(0124578)$ & $7-Z 17(0124569)$ & $7-26(0134579)$ & \\
$7-15(0124678)$ & $7-21(0124589)$ & $7-31(0134679)$ & \\
$7-11(0134568)$ & $7-20(0125679)$ & $7-32(0134689)$ & \\
$7-Z 37(0134578)$ & $7-22(0125689)$ & $7-28(0135679)$ & \\
$7-8(0234568)$ & $7-Z 18(0145679)$ & $7-23(0234579)$ & \\
& & $7-25(0234679)$ & \\
\hline
\end{tabular}

Cardinality 8:

\begin{tabular}{|c|c|c|c|}
\hline PCORD & $\mathbf{( ( 1 1 1 1 1 1 1 ) )}$ & $\mathbf{( ( 1 1 1 1 1 1 2 ) )}$ & $\mathbf{( ( 1 1 1 1 1 1 3 ) )}$ \\
\hline Set Class & $8-1(01234567)$ & $8-2(01234568)$ & $8-3(01234569)$ \\
& & $8-4(01234578)$ & $8-7(01234589)$ \\
& & $8-5(01234678)$ & $8-8(01234789)$ \\
& & $8-6(01235678)$ & $8-9(01236789)$ \\
\hline
\end{tabular}

\begin{tabular}{|c|c|}
\hline $\mathbf{( ( 1 1 1 1 1 2 2 ) )}$ & $\mathbf{( ( 1 1 1 1 2 2 2 ) )}$ \\
\hline $8-11(01234579)$ & $8-21(0123468 \mathrm{~T})$ \\
$8-13(01234679)$ & $8-22(0123568 \mathrm{~T})$ \\
8-Z-15(01234689) & $8-23(0123578 \mathrm{~T})$ \\
8-Z29 (01235679) & $8-24(0124568 \mathrm{~T})$ \\
8-18 (01235689) & $8-27(0124578 \mathrm{~T})$ \\
$8-16(01235789)$ & $8-25(0124678 \mathrm{~T})$ \\
$8-14(01245679)$ & $8-26(0134578 \mathrm{~T})$ \\
$8-19(01245689)$ & $8-28(0134679 \mathrm{~T})$ \\
$8-20(01245789)$ & \\
8-12 (01345679) & \\
8-17(01345689) & \\
8-10(02345679) & \\
\hline
\end{tabular}


MUSICA THEORICA Revista da Associação Brasileira de Teoria e Análise Musical 2018, v. 3, n. 2, p. 46-85 - Journal of the Brazilian Society for Music Theory and Analysis@ TeMA 2018 - ISSN 2525-5541

Cardinality 9:

\begin{tabular}{|c|c|c|c|}
\hline PCORD & $\mathbf{( ( 1 1 1 1 1 1 1 1 ) )}$ & $\mathbf{( ( 1 1 1 1 1 1 1 2 ) )}$ & $\mathbf{( ( 1 1 1 1 1 1 2 2 ) )}$ \\
\hline Set Class & $9-1(012345678)$ & $9-2(012345679)$ & $9-6(01234568 \mathrm{~T})$ \\
& & $9-3(012345689)$ & $9-7(01234578 \mathrm{~T})$ \\
& & $9-4(012345789)$ & $9-8(01234678 \mathrm{~T})$ \\
& & $9-5(012346789)$ & $9-9(01235678 \mathrm{~T})$ \\
& & & $9-10(01234679 \mathrm{~T})$ \\
& & & $9-11(01235679 \mathrm{~T})$ \\
& & $9-12(01245689 \mathrm{~T})$ \\
\hline
\end{tabular}

We can call attention for the case of cardinality 3 where each set class is associated univocally with one PCORD. As cardinality increases, we find that the average number of members of each PCORD grouping also increases. When we reach cardinality $8-9$, the number may be excessive to be analytically useful.

\section{Analysis as reverse engineering: PCORD as a generative vector}

When we think about analysis of post-tonal music, in especial of music of the second half of the $20^{\text {th }}$ century, we often call analysis findings that are just reverse engineering. A simple example illustrates the idea. If you do not understand how a machine works, you may disassemble its parts, realize what role they perform, and reassemble it. Many analytical studies of music follow this procedure. For instance, an analysis of Le Marteau sans Maître by Boulez that explains how a boulezian operation of multiplication generates a combinatorial matrix and how that matrix maps onto the score. Or, if you consider the stochastic music of Xenakis, all you need is to discover the probability distribution that control pitches and maybe other parameters. In both cases, the purpose of the analysis is just to understand how to generate the same product based in the same principles. The discussion of the principles seems more or less redundant.

According to this kind of analysis, all we need to know about a piece that had been composed using PCORD relations, is the set of unordered intervals that generated the pitch sets found in the music. There are only 45 possibilities, according to the table of item 6, because of the 66 sets we need to deduce 21 that do not have a correspondent pair, what makes them useless to generate some related sets.

To generate music with PCORDs the first step is to choose a tool-set of intervals, as the sequence 12234 on Figure 4. The last number, 4, is irrelevant because it is always the result of 12 minus the others intervals. Therefore, the PCORD vector ((1223)) represents the set of intervals in Figure 4. 


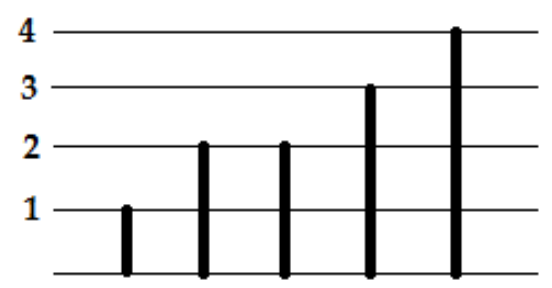

Figure 4: Set of intervals 12234 represented by the length of line segments

After that, you shuffle the intervals in different orders to produce as many different set configurations as you might have. Table Cardinality 6 tells us that in this case there are six possible configurations. Among them, the two configurations displayed in Figure 5.
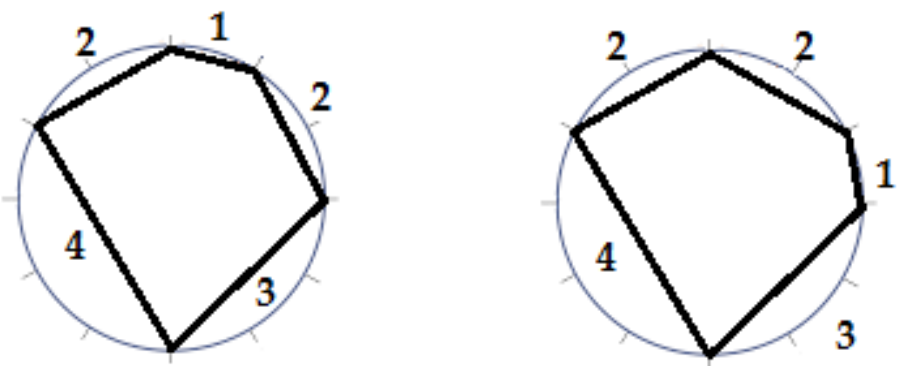

Figure 5: Two different set configurations generated by PCORD $=((1223))$

The problem becomes more interesting when you start to consider how similar these sets are. The visual form tells us that they have similarities and differences. How to account to them? Forte and others have chosen to compare them using interval vectors. We choose to compare their trichords because PCORD-3 are unique and representative of harmonic perceptual properties. This is the same as to compare all triangles drawn from the vertices (Figure 6). 

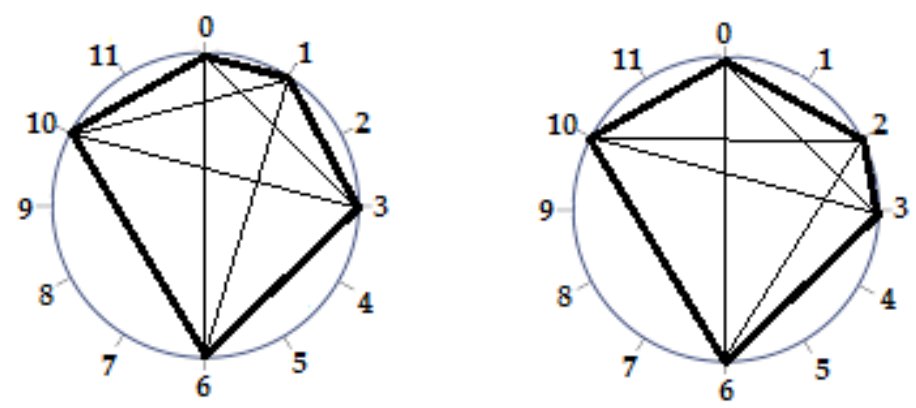

Figure 6: Two different configurations of sets generated by PCORD ((1223))

The list of triangles, represented by the number of their vertices, that the configurations of Figure 6 produce is listed on Figure 7.

\begin{tabular}{|c|c|c|c|}
\hline ((12)) & 0 & 13 & ((12)) \\
\hline ((15)) & 0 & 16 & $((24))$ \\
\hline$((12))$ & 0 & 110 & $((22))$ \\
\hline ((33)) & 0 & 36 & $((33))$ \\
\hline ((23)) & 0 & $\begin{array}{ll}3 & 10\end{array}$ & $((23))$ \\
\hline ((24)) & 0 & $\begin{array}{ll}6 & 10\end{array}$ & $((24))$ \\
\hline$((23))$ & & 36 & ((13)) \\
\hline ((23)) & 1 & 310 & $((14))$ \\
\hline ((34)) & 1 & $\begin{array}{ll}6 & 10\end{array}$ & $((44))$ \\
\hline$((34))$ & 3 & $\begin{array}{ll}6 & 10\end{array}$ & ((34)) \\
\hline
\end{tabular}

Figure 7: Trichords of each configuration with respective PCORDs (five identities)

There are five matches among ten triangles: just 50\% of the total. This seems a low index of similarity since the configurations look quite similar. They share the quadrilateral 0-3-6-10 and the triangles 0-1-3 and 0-2-3 of the upper part are the same, but mirrored. Based on the reasoning, we would expect a higher number of matches. This means that, as index of similarity, a trichord vector is very sensible. A result of $50 \%$ already represents good resemblance.

Soderberg (1998) considers that Z-related sets are isomeric, ${ }^{7}$ insofar they are entities containing the same numbers of the same kinds of elements but arranged differently. Perhaps PCORDs could be considered another instance of isomerism. I prefer the concept of isocanonic (from canon = law) because PCORD related sets follow the same generative rule.

\footnotetext{
7 "The term 'isomeric', [...] was originally used by Hanson (1960) to refer to what we call now ' $\mathrm{z}$ related' sets" (Soderberg 1998, p. 217).
} 
Another way of looking at this problem concerns the voice leading that transforms the first configuration into the second or vice-versa. Just one pitch moves one semitone up or down. This is the best parsimony that you can get. Indeed, most PCORD-related sets could also be generated by smooth voiceleading transformations. We will explore this property on topic 9 of this paper.

\section{Analytical examples of PCORD relations}

Given its nature, we should expect that the PCORD relations have limited analytical application, as also happens with the Z-relations. Notwithstanding, we have already pointed out that most set classes, except those of cardinality 3 , exhibit a PCORD pair. All exceptions coincide with some interval-cycle: six to interval-cycle-1 (clusters), three to interval-cycle-2 (whole-tone) and one to interval-cycle-3 (diminished seventh). This observation increases our expectations of finding meaningful PCORD-relations in the repertoire.

\section{8a. Excerpt from Santoro's Sonata 1942}

Let us start with the excerpt of Santoro's Sonata 1942 shown on Example 1. The passage was analyzed with a segmentation in sets of five pitches that resulted in four different set classes. It would be amazing if they reveal some PCORD relation between them. Matching PCORDs and set classes, we find the following results: 5-6 (01256) $\rightarrow((1113)) ; 5-Z 18(01457) \rightarrow((1123)) ; 5-27(01358) \rightarrow$ $((1223)) ; 5-23$ (02357) $\rightarrow$ ((1222)). Conclusion: there are no PCORD matches.

This result should be expected. The literature shows that this piece uses twelve-tone technique (Larsen, 2011). Only by some odd chance, our aleatory segmentation in sets of five notes would reveal some consistency. Although there are many PCORDs groups of cardinality 5 with 6 or 4 set classes, nothing assures that aleatory segmentations will coincide in PCORD classes.

\section{8b. Parks's analysis of Debussy's music}

We expected that Parks' analyses of Debussy's music, particularly those based on the set genera reproduced on Figure 2, might provide us some musical examples of PCORD-relations. Unfortunately for our purposes, his results are usually standard set genera analysis based on set repetition, inclusion and complement, without connection to the set genera identity of Figure 2. 
MUSICA THEORICA Revista da Associação Brasileira de Teoria e Análise Musical 2018, v. 3, n. 2, p. 46-85 - Journal of the Brazilian Society for Music Theory

Occasionally, in other analysis of the same book, we found some instances of PCORD relations:

1. "Example 6.1" (Parks 1989, p. 134) of the movement Lent from Images shows a diatonic collection 8-23 on $\mathrm{mm}$. 24-26, and another diatonic collection, this time a 8-22, on mm. 32-35. These two sets are PCORD related. However, we must consider a little far-fetched to claim that this relation is structurally meaningful to the piece, given that it happens once, near the end of the piece, and with a large distance between the extracts.

2. "Example 6.2" (Parks 1989, p. 136) of Le jete d'eau shows a sequence of three diatonic collections PCORD-related: 7-34 (mm. 1-6), 7-35 (mm. 18-19) and 7-33 (mm. 20-22). This example is more convincing because the extract can be interpreted as a sequence of transformations: the acoustic scale becomes a diatonic and finally a whole-tone scale with an extra pitch that holds its vagrant symmetry in one axis.

\section{8c. Excerpt from Villa-Lobos' Rudepoema}

Villa-Lobos' Rudepoema gives us a better example of some PCORD links, as shown on Example 2 (reproduced from Coelho de Souza 2012, p. 218).
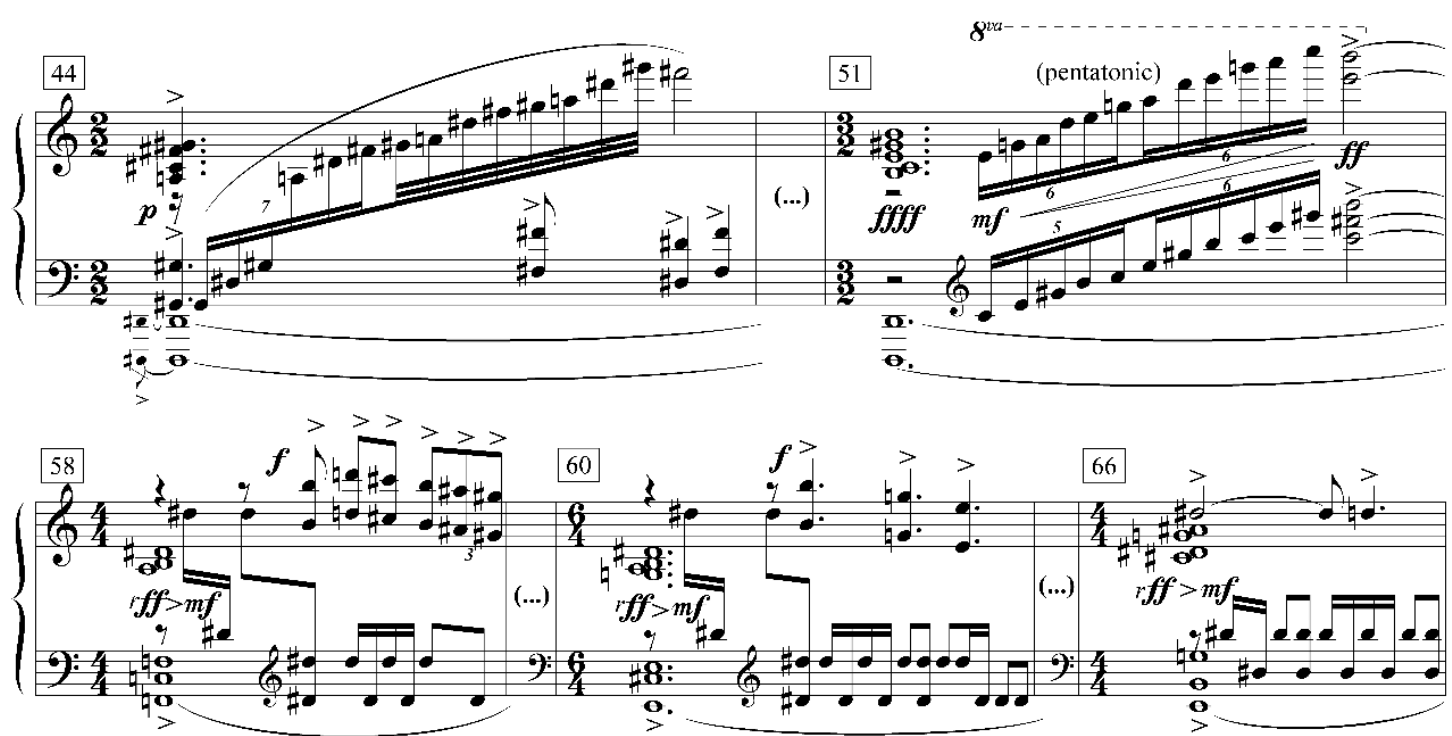

Example 2: Excerpt from Villa-Lobos' Rudepoema (measures are numbered) five set classes links generated by PCORD $=((1223))$

For our analytical purposes, we hope to find juxtaposed sets related by PCORD. However, the passage features standard paradigmatic collections (not shown on Example 2): octatonic, diatonic, whole-tone and pentatonic (this one 
appears on measure 51, left hand). Then, our interest is drawn to the enigmatic sets that interpolate those sets. They don't seem to make much sense in relation to the surroundings. But, when we consider the whole section, they turn to be pillars of a long-term structure, pivot chords for smooth voice-leading modulation between the paradigmatic collections. These links are built upon PCORD-related set classes. The analysis of Example 2 gives us the following results:

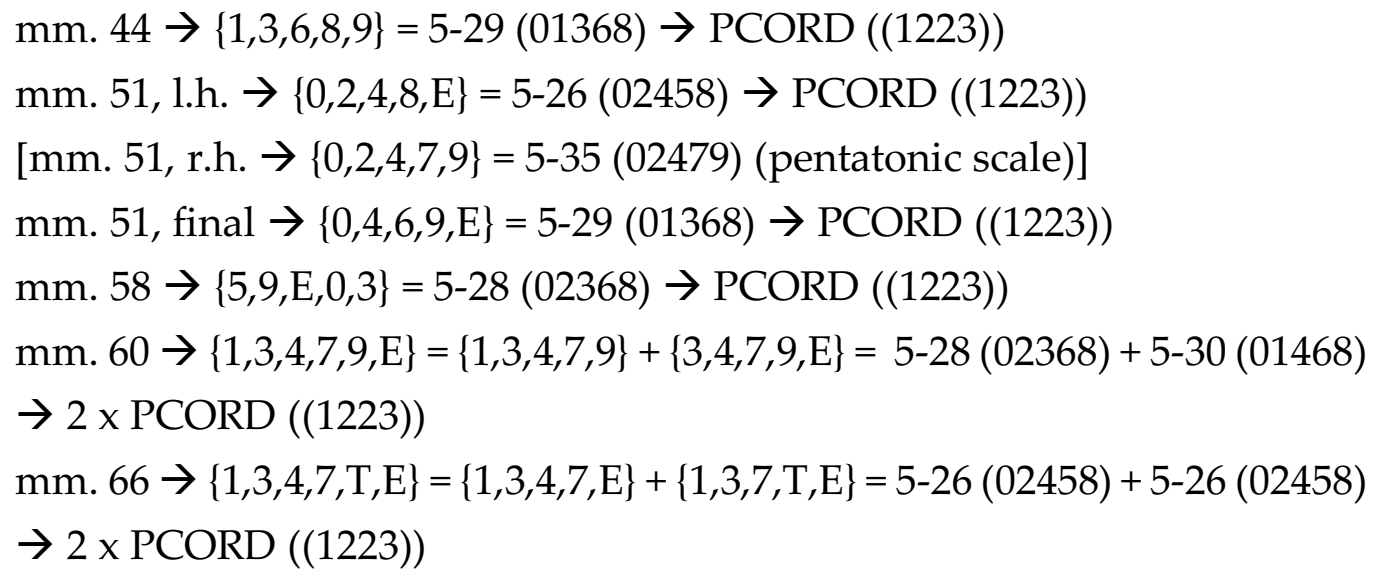

Notice that measures 60 and 66 demanded us to stretch the analytical hypothesis to explain these six-notes sets as the combination of two five-notes sets. Processes of inclusion like this follow a long analytical tradition in set theory, since its beginnings with Forte. Therefore, it seems quite reasonable to consider these set classes (01368), (02458), (02368) e (01468), all related by PCORD ((1223)), as responsible for the logic of this passage. Some of these collections have also links to larger collections, like 5-28 (02368) that is a sub-set of the octatonic collection 8-28 (0134679T). This can also mean that the network of similarities between the sets used by the composer in this passage is still larger and more complex than the example was able to grasp. Probably the composer employed a personal logic of interval permutation that produced the diversity of set formations used in this passage, which can be interpreted with the theory of PCORD related sets.

\section{8d. Excerpt from Hans Otte's Das Buch der Klänge 2}

Das Buch der Klänge 2 for piano (1982) by Hans Otte is minimalistic music that uses standard set class consistency throughout the composition, with sets of cardinality 5 and 6 . Nevertheless, there are some few passages that seems to fail this general principle, as shown in Example 3. This excerpt shows set inclusion 
MUSICA THEORICA Revista da Associação Brasileira de Teoria e Análise Musical 2018, v. 3, n. 2, p. 46-85 - Journal of the Brazilian Society for Music Theory

of cardinality 5 in 6, besides repetition, as also happens in the rest of the composition. Some different set classes that appear to be unrelated to the others, the analysis demonstrates, belong to four set classes related by PCORD, therefore keeping consistency in another level.
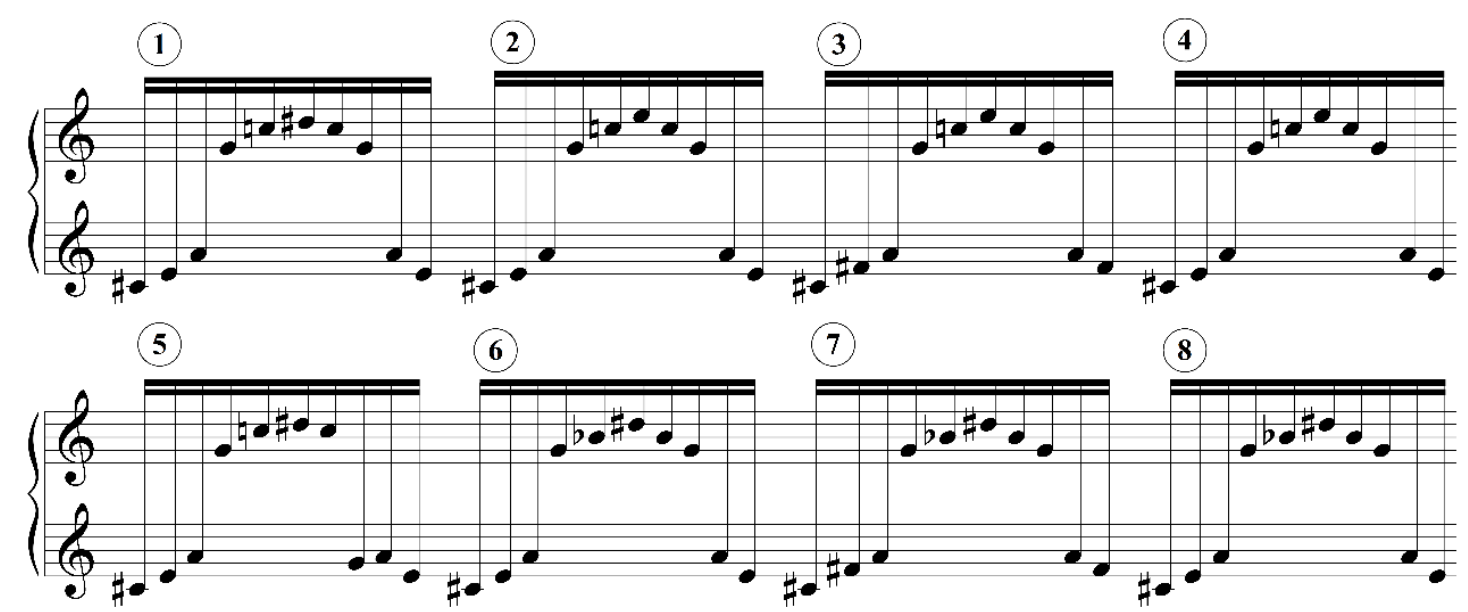

\begin{tabular}{|c|c|c|c|c|}
\hline & Pitches & Pitch-numbers & Set-Class & PCORD \\
\hline 1 & C,C\#,D\#,E,G,A & $0,1,3,4,7,9$ & $6-Z 49(013479)$ & $((11223))$ \\
\hline 2 & C,C\#,E,G,A & $0,1,4,7,9$ & $5-32(01469)$ & {$[5-32 \in 6-Z 49]$} \\
\hline 3 & C,C\#,E,F\#,G,A & $0,1,4,6,7,9$ & $6-Z 50(014679)$ & $((11223))$ \\
\hline 4 & C,C\#,E,G,A & $0,1,4,7,9$ & $5-32(01469)$ & {$[5-32 \in 6-Z 49]$} \\
\hline 5 & C,C\#,D\#,E,G,A & $0,1,3,4,7,9$ & $6-Z 49(013479)$ & $((11223))$ \\
\hline 6 & C\#,D\#,E,G,A,Bb & $1,3,4,7,9, \mathrm{~T}$ & $6-30(013679)$ & $((11223))$ \\
\hline 7 & C\#,D\#,F\#,G,A,Bb & $1,3,6,7,9, \mathrm{~T}$ & $6-\mathrm{Z} 49(013479)$ & $((11223))$ \\
\hline 8 & C\#,D\#,E,G,A,Bb & $1,3,4,7,9, \mathrm{~T}$ & $6-30(013679)$ & $((11223))$ \\
\hline
\end{tabular}

Example 3: Hans Otte's Das Buch der Klänge 2 (1982,) chord-groups 38 through 45

We may emphasize that a standard set class analysis alone would not be able to demonstrate the organic consistency of this passage. This excerpt uses four instances of three different set classes of cardinality 6 (6-30, 6-Z49 and 6-Z50) which are related by PCORD and one set class of cardinality 5 that is a segment of 6-Z49, besides repetition. An inspection of the entire composition shows that all sets used here belong to a tight network of set classes, with occasional PCORD similarity, used when the group does not fit a traditional set class relation. 


\section{8e. Excerpt from Coelho de Souza's Dialogues}

Perhaps is not fair to use examples of my own music to validate the theory that I am presenting. Maybe so, but as a composer I praise theories that are not just reverse engineering, but also useful tools for new developments.

Dialogues (1987) for marimba and vibraphone, when analyzed nowadays, reveals a hidden network of PCORD relations, even though the PCORD relation theory had not been proposed at that time. As Cervo (2005) observed, this computer-assisted composition uses an algorithm that sorts intervals to produce five-notes sets moving with controlled parsimony and displacements on rhythmic figurations. This procedure of controlled juxtaposition follows Rahn's (1979) principle of logical paths, blending naturally with PCORD consistency.
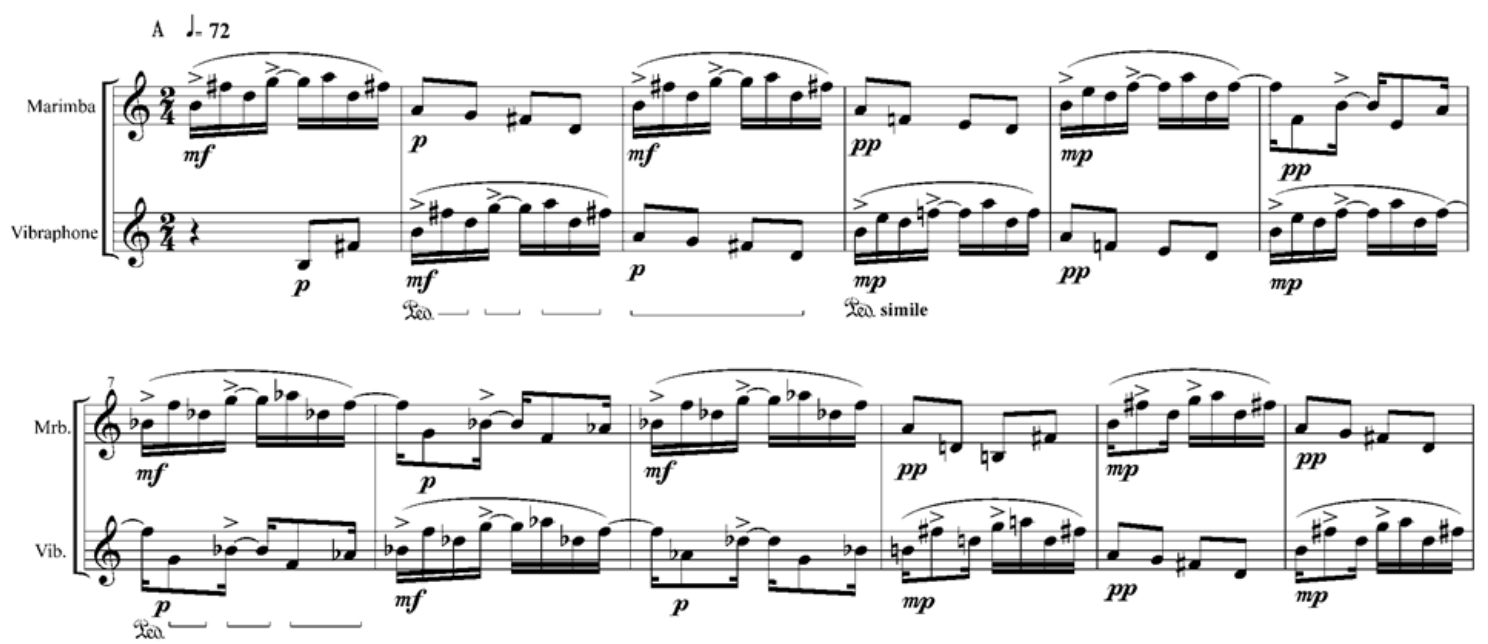

Example 4: Coelho de Souza's Dialogues (1987) mm. 1-12

The process of imitation suggests a natural segmentation in groups of three measures featuring sets of five pitches. Reducing to set classes we get:

$$
\begin{array}{ll}
\text { mm. 1-3 } & \rightarrow \mathrm{A}=\{2,6,7,9, \mathrm{E}\}=5-27(01358) \\
\mathrm{mm} .4-6 & \rightarrow \mathrm{B}=\{2,4,5,9, \mathrm{E}\}=5-29(01368) \\
\mathrm{mm} .7-9 & \rightarrow \mathrm{C}=\{1,5,7,8, \mathrm{~T}\}=5-25(02358) \\
\mathrm{mm} .10-12 & \rightarrow \mathrm{A}^{\prime}=\{2,6,7,9, \mathrm{E}\}=5-27(01358)
\end{array}
$$

At measure 10, the music returns to the first set with a different rhythm. The analysis shows that the three first sets belong to different set classes. Therefore, it might seem that we had reached a similar dead end to our analysis of Santoro's Piano Sonata 1952.

However, although the sets have different prime forms, they are PCORD related: 
MUSICA THEORICA Revista da Associação Brasileira de Teoria e Análise Musical 2018, v. 3, n. 2, p. 46-85 - Journal of the Brazilian Society for Music Theory and Analysis @ TeMA 2018 - ISSN 2525-5541

$$
\begin{array}{ll}
\mathrm{A}=5-27(01358) & \rightarrow \operatorname{PCORD}((1223)) \\
\mathrm{B}=5-29(01368) & \rightarrow \operatorname{PCORD}((1223)) \\
\mathrm{C}=5-25(02358) & \rightarrow \operatorname{PCORD}((1223))
\end{array}
$$

Another way to look at this problem is that these set classes resulted of Ars Combinatoria applied to intervals:
Set class:

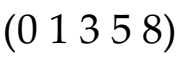
(0 103668$)$
APIC vectors: 1223

These three sets feature the same intervals in different order. Notice that this procedure is idiomatic to an algorithmic treatment in computer-assisted composition.

\section{8f. Excerpt from Coelho de Souza's Metropolis (1990)}

Example 5 has some formal similarities with Example 4, but there is a significant difference. In Example 4 the basic procedure was juxtaposition of PCORD-related sets. Example 5 features the procedure of condensation. This idea of adding related set classes to form larger collections, as we saw in Villa-Lobos, allows the composer to control pitch saturation, which may range from the cardinality of a single set class to the aggregate.

We may realize that each of these measures has a different number of pitch-classes, ranging from 6 to 10. Although there is variation of pitch-class density, this example does not feature the aggregate. Later on the piece, the aggregate will be a goal to be reached. Notice also the pervasive use of repetition. This is a perceptive strategy, often used by Debussy as pointed by Eimert (1961, p. 11). ${ }^{8}$

\footnotetext{
8 "All themes (motives) of Jeux appear at least twice; most of them are repeated immediately" (Eimert 1961, p. 11).
} 

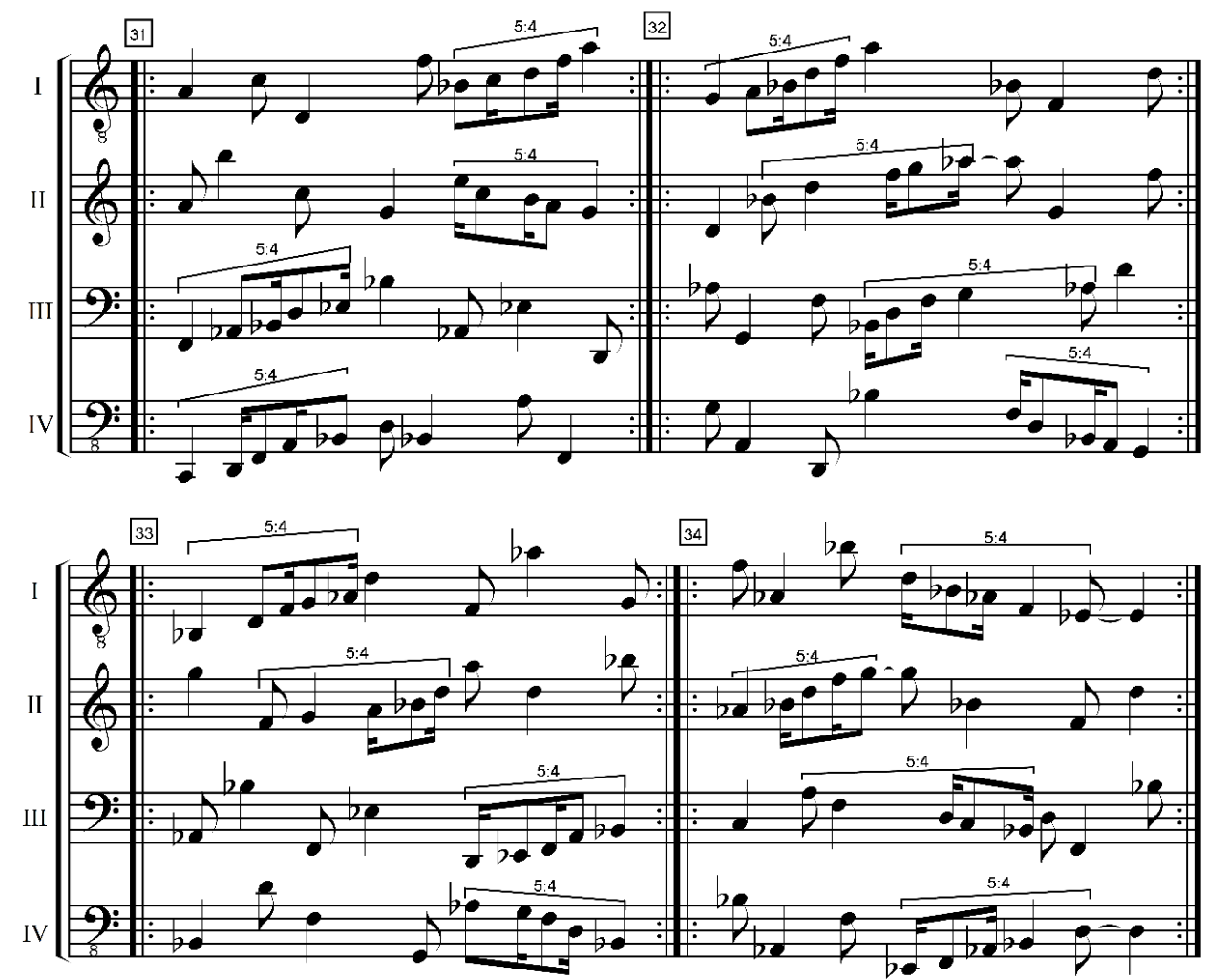

\begin{tabular}{|c|c|c|c|c|}
\hline Measure/Voice & Pitches & Normalized & Set-Class & PCORD \\
\hline $31-\mathrm{I}$ & $\{\mathrm{A}, \mathrm{C}, \mathrm{D}, \mathrm{F}, \mathrm{Bb}\}$ & {$[0,2,5,9, \mathrm{~T}]$} & $5-27(01358)$ & $((1223))$ \\
\hline $31-\mathrm{II}$ & $\{\mathrm{A}, \mathrm{B}, \mathrm{C}, \mathrm{G}, \mathrm{E}\}$ & {$[0,4,7,9, \mathrm{E}]$} & $5-27(01358)$ & $((1223))$ \\
\hline $31-\mathrm{III}$ & $\{\mathrm{F}, \mathrm{Ab}, \mathrm{Bb}, \mathrm{D}, \mathrm{Eb}\}$ & {$[2,3,5,8, \mathrm{~T}]$} & $5-29(01368)$ & $((1223))$ \\
\hline $31-\mathrm{IV}$ & $\{\mathrm{C}, \mathrm{D}, \mathrm{F}, \mathrm{A}, \mathrm{Bb}\}$ & {$[0,2,5,9, \mathrm{~T}]$} & $5-27(01358)$ & $((1223))$ \\
\hline $32-\mathrm{I}$ & $\{\mathrm{G}, \mathrm{A}, \mathrm{Bb}, \mathrm{D}, \mathrm{F}\}$ & {$[2,5,7,9, \mathrm{~T}]$} & $5-27(01358)$ & $((1223))$ \\
\hline $32-\mathrm{II}$ & $\{\mathrm{D}, \mathrm{Bb}, \mathrm{F}, \mathrm{G}, \mathrm{Ab}\}$ & {$[2,5,7,8, \mathrm{~T}]$} & $5-25(02358)$ & $((1223))$ \\
\hline $32-\mathrm{III}$ & $\{\mathrm{Ab}, \mathrm{G}, \mathrm{F}, \mathrm{Bb}, \mathrm{D}\}$ & {$[2,5,7,8, \mathrm{~T}]$} & $5-25(02358)$ & $((1223))$ \\
\hline $32-\mathrm{IV}$ & $\{\mathrm{G}, \mathrm{A}, \mathrm{D}, \mathrm{Bb}, \mathrm{F}\}$ & {$[2,5,7,9, \mathrm{~T}]$} & $5-27(01358)$ & $((1223))$ \\
\hline $33-\mathrm{I}$ & $\{\mathrm{Bb}, \mathrm{D}, \mathrm{F}, \mathrm{G}, \mathrm{Ab}\}$ & {$[2,5,7,8, \mathrm{~T}]$} & $5-25(02358)$ & $((1223))$ \\
\hline $33-\mathrm{II}$ & $\{\mathrm{G}, \mathrm{F}, \mathrm{A}, \mathrm{Bb}, \mathrm{D}\}$ & {$[2,5,7,9, \mathrm{~T}]$} & $5-27(01358)$ & $((1223))$ \\
\hline $33-\mathrm{III}$ & $\{\mathrm{Ab}, \mathrm{Bb}, \mathrm{F}, \mathrm{Eb}, \mathrm{D}\}$ & {$[2,3,5,8, \mathrm{~T}]$} & $5-29(01368)$ & $((1223))$ \\
\hline $33-\mathrm{IV}$ & $\{\mathrm{Bb}, \mathrm{D}, \mathrm{F}, \mathrm{G}, \mathrm{Ab}\}$ & {$[2,5,7,8, \mathrm{~T}]$} & $5-25(02358)$ & $((1223))$ \\
\hline $34-\mathrm{I}$ & $\{\mathrm{F}, \mathrm{Ab}, \mathrm{Bb}, \mathrm{D}, \mathrm{Eb}\}$ & {$[2,3,5,8, \mathrm{~T}]$} & $5-29(01368)$ & $((1223))$ \\
\hline $34-\mathrm{II}$ & $\{\mathrm{Ab}, \mathrm{Bb}, \mathrm{D}, \mathrm{F}, \mathrm{G}\}$ & {$[2,5,7,8, \mathrm{~T}]$} & $5-25(02358)$ & $((1223))$ \\
\hline $34-\mathrm{III}$ & $\{\mathrm{C}, \mathrm{A}, \mathrm{F}, \mathrm{D}, \mathrm{Bb}\}$ & {$[0,2,5,9, \mathrm{~T}]$} & $5-27(01358)$ & $((1223))$ \\
\hline $34-\mathrm{IV}$ & $\{\mathrm{Bb}, \mathrm{Ab}, \mathrm{F}, \mathrm{Eb}, \mathrm{D}\}$ & {$[2,3,5,8, \mathrm{~T}]$} & $5-29(01368)$ & $((1223))$ \\
\hline
\end{tabular}

Example 5: Excerpt from Coelho de Souza's Metropolis mm. 31-34 for electronic sounds (notice: voice I sounds $8^{\mathrm{a}}$ higher, and voice IV $8^{\mathrm{a}}$ lower) 


\section{Parsimony between set classes on PCORD spaces}

A theory of voice-leading parsimony after PCORD, yields some interesting differences from the view derived from set classes. In Figure 8, we may compare the differences between the voice-leading space for trichords based on set classes and PCORDs.
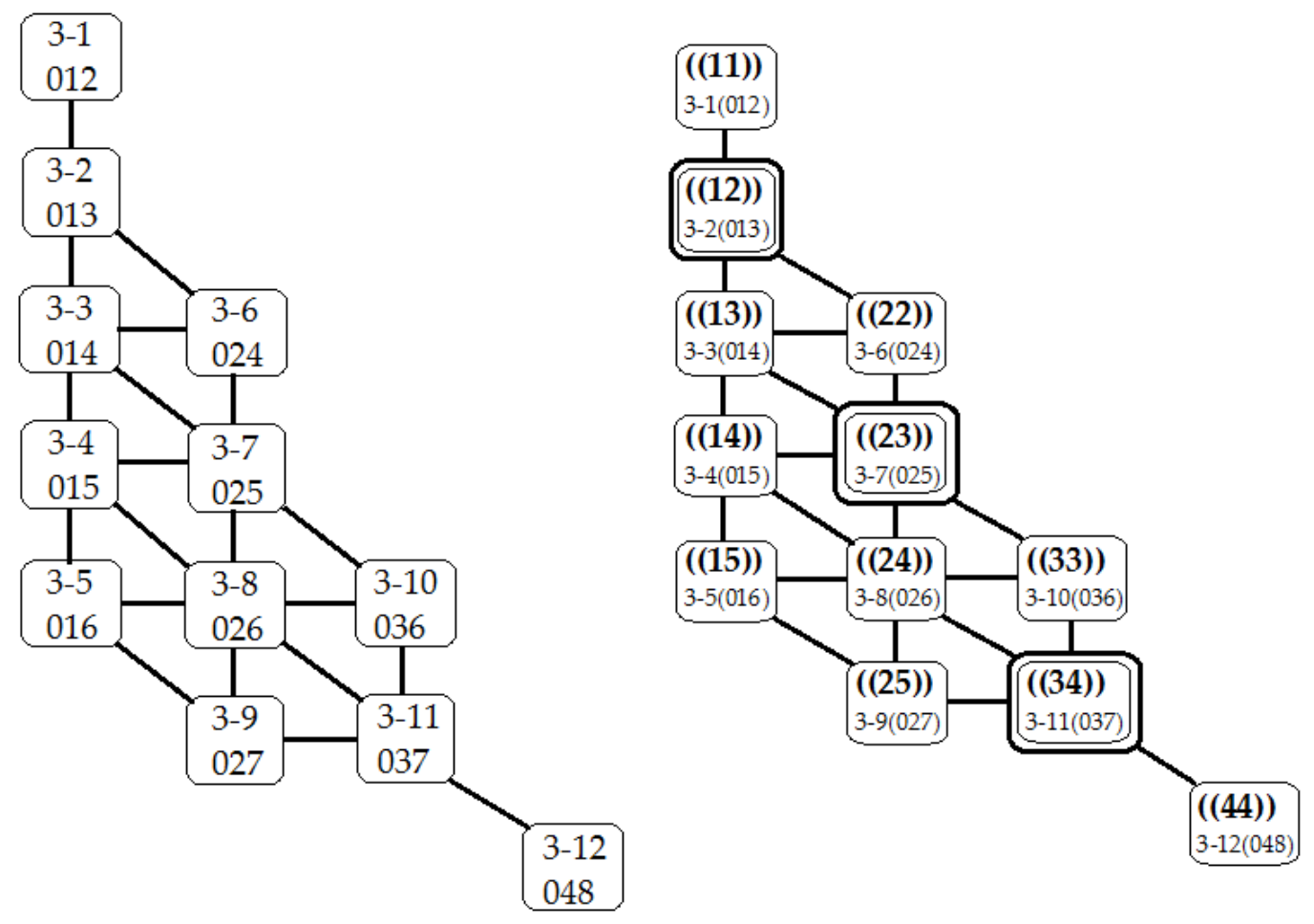

Figure 8: Voice-leading space for sets of cardinality 3. On the left: based on set classes (after Straus, 2016); On the right: based on PCORDs

Notice that the grid of relations is the same. We marked with a double rectangle the PCORDs ((12)), ((23)) and ((34)), whose idiomatic internal permutations allow the generation of other parsimonious sets. For instance: ((12)) can generate $\{0,1,3\}$ and its internal permutation ((21)) can generate other set, $\{0,2,3\}$, that is parsimonious. The equivalent in set classes would be to realize that sets 3-2 (013), 3-7 (025) and 3-11 (037) can generate inverted sets that are parsimonious with the original. Notice also that, in each line, the sum of the intervals of every PCORD is the same. The grids for other cardinalities will hold the same standard.

For the case of cardinality 4, we think there is an advantage of plotting the parsimony based on PCORDs, instead of set classes. Figures 9 and 10 compare voice-leading spaces for each solution. 


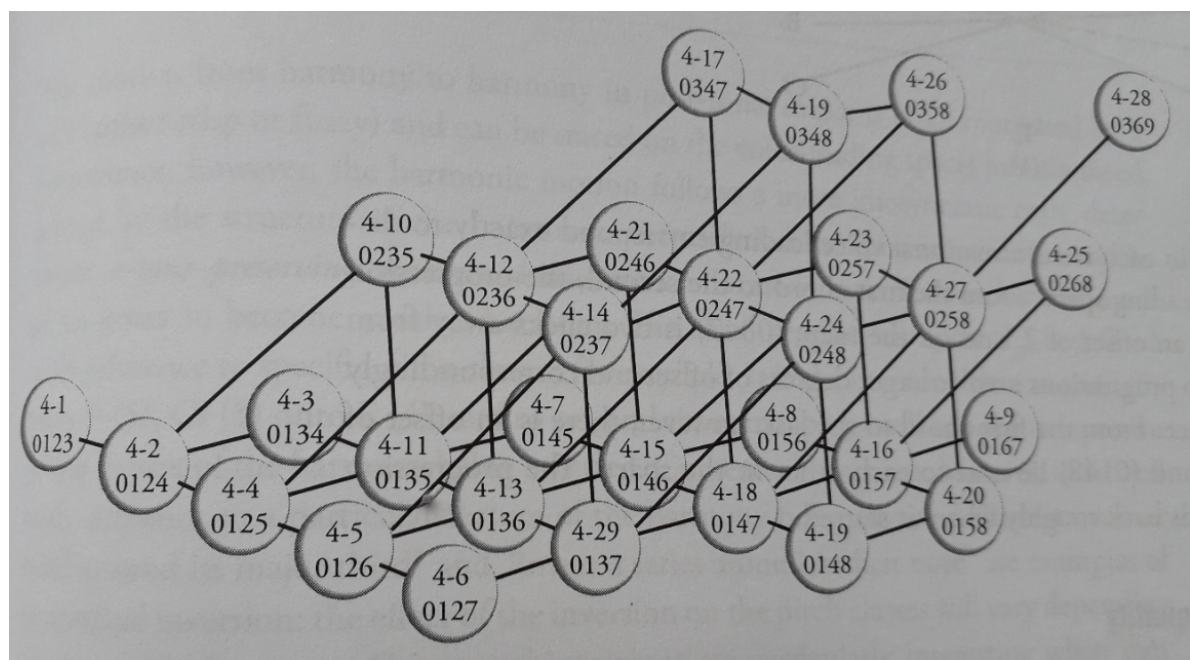

Figure 9: Voice-leading space for cardinality 4 based on set classes (after Straus, 2016)

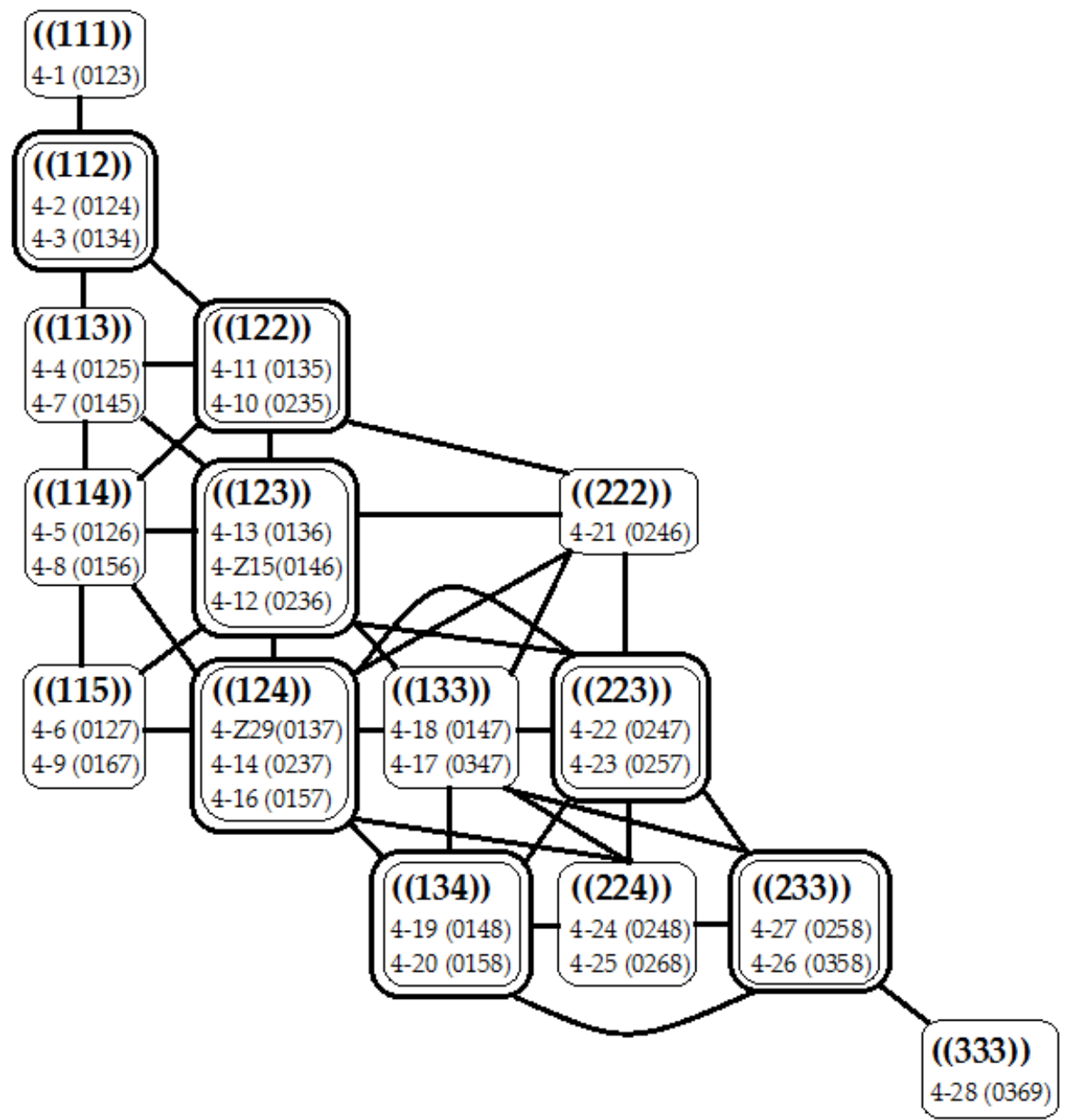

Figure 10: Voice-leading space for cardinality 4 based on PCORDs 
The parsimonious voice-leading space with set classes of Figure 9 requires a tri-dimensional representation. It may seem more adventurous than a twodimensional representation, but it is harder to grasp its content. Figure 9 features 30 nodes and has required an artificial repetition of the set class 4-19, marked as (0148) on the bottom and as (0348) on the top, to fix the problem of the parsimony space, despite that the set class (0348) does not exist, it is just an instance of (0148).

On the other hand, the PCORD representation of Figure 10 uses half of the nodes, just 15, and allows connections that are more complex. Indeed, each PCORD connects to every other PCORD of its surroundings. Double rectangles, following the same convention we set for the trichords, mean that the enclosed PCORD can generate other parsimonious sets by internal permutation of elements.

While the complexity of the problem of plotting a space of parsimonious voice-leading seems to increase when we consider set classes of higher cardinality, with PCORD the complexity remains more or less the same. For cardinality 5 there are 38 set classes related to 13 PCORDs. Straus (2016) does not provide a representation for this case. In Figure 11 we provide our solution for this case. The meaning of double rectangles keeps the convention established for other figures. 


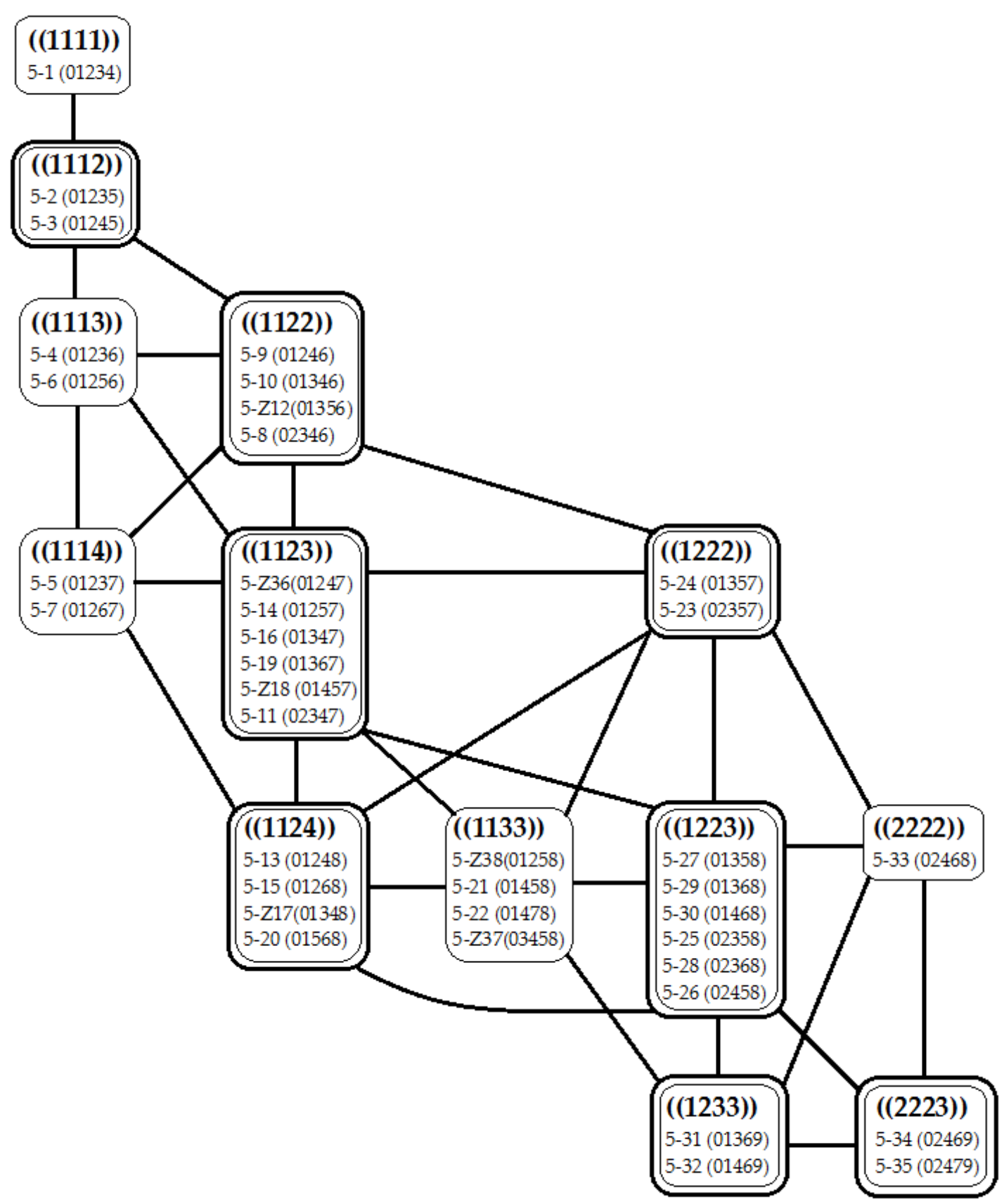

Figure 11: Voice-leading space for sets of cardinality 5 based on PCORDs

For the sake of completing the voice-leading for all cardinalities, Figures $12,13,14$ and 15 provide similar voice-leading spaces for cardinalities $6,7,8$ and 9. 
MUSICA THEORICA Revista da Associação Brasileira de Teoria e Análise Musical 2018, v. 3, n. 2, p. 46-85 - Journal of the Brazilian Society for Music Theory and Analysis @ TeMA 2018 - ISSN 2525-5541

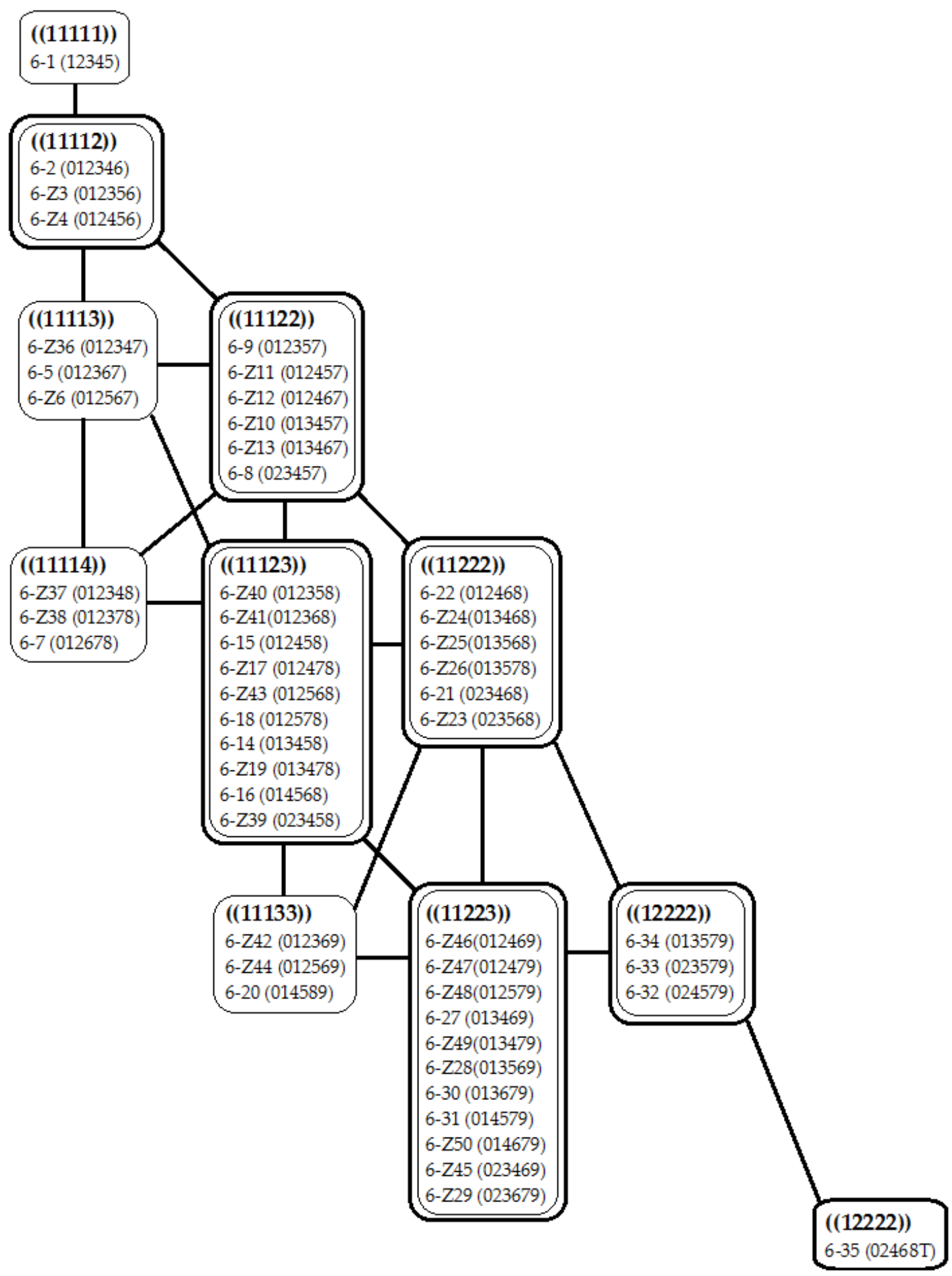

Figure 12: Voice-leading space for sets of cardinality 6 based on PCORDs 


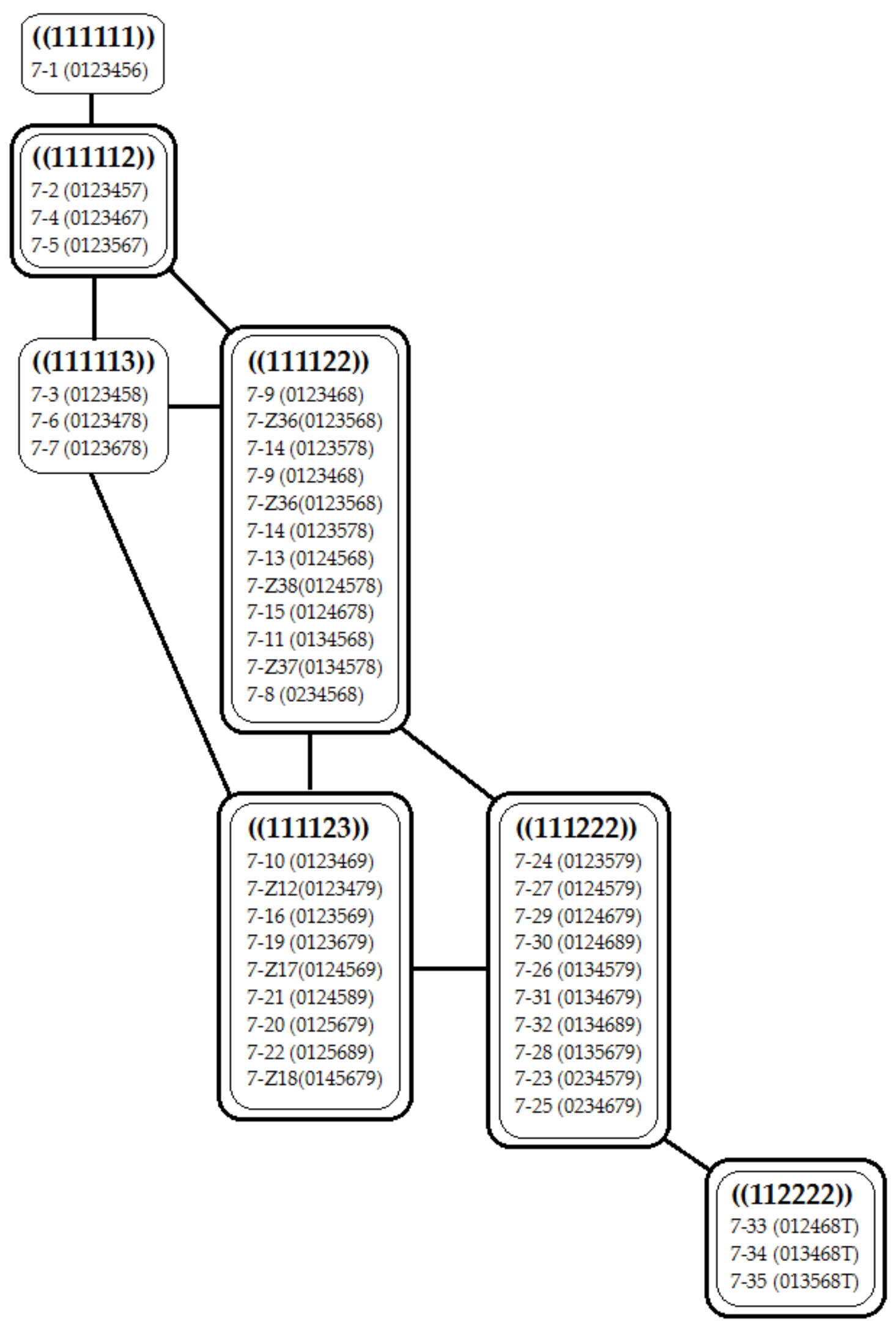

Figure 13: Voice-leading space for sets of cardinality 7 based on PCORDs 
MUSICA THEORICA Revista da Associação Brasileira de Teoria e Análise Musical 2018, v. 3, n. 2, p. 46-85 - Journal of the Brazilian Society for Music Theory and Analysis @ TeMA 2018 - ISSN 2525-5541

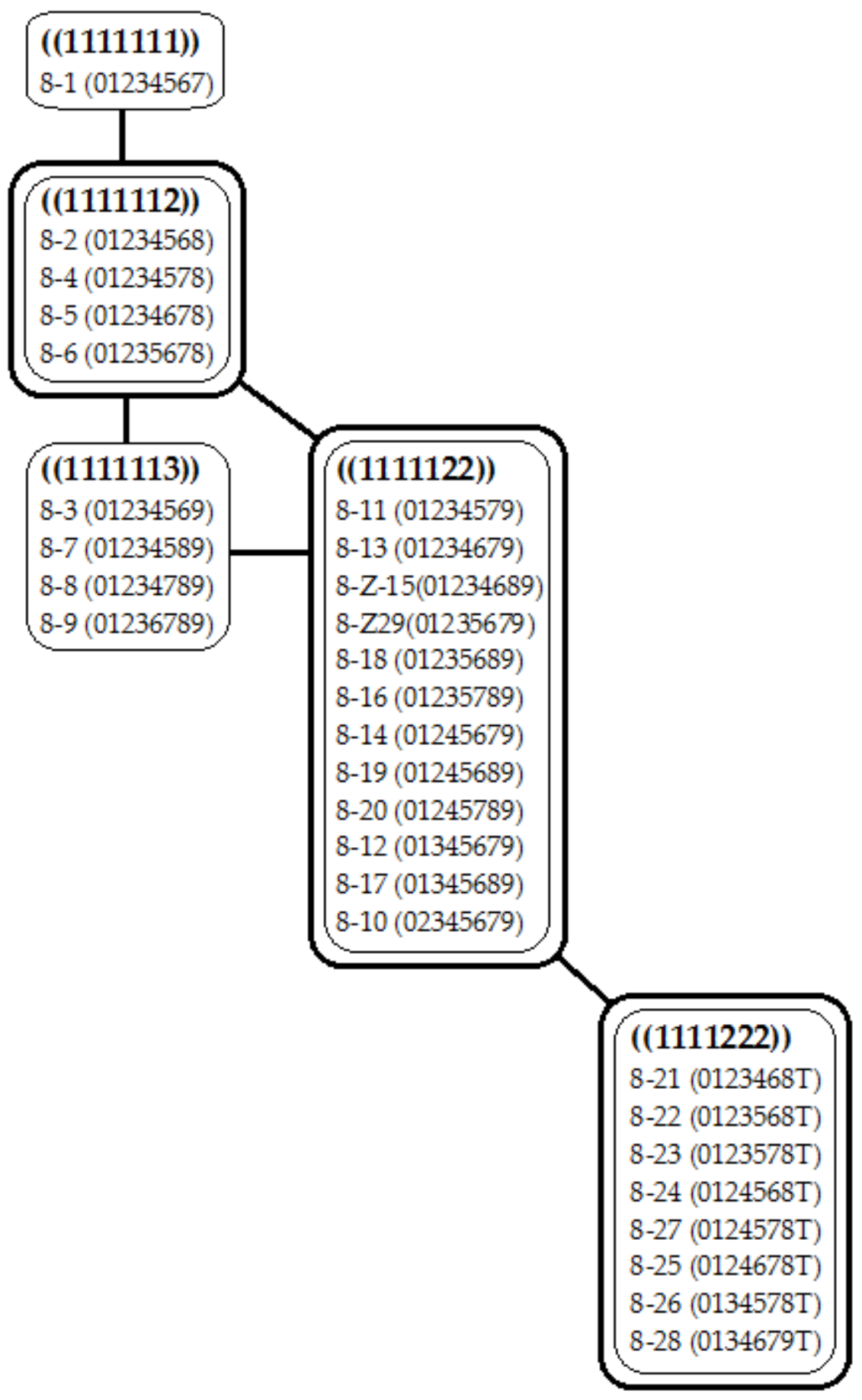

Figure 14: Voice-leading space for sets of cardinality 8 based on PCORDs 


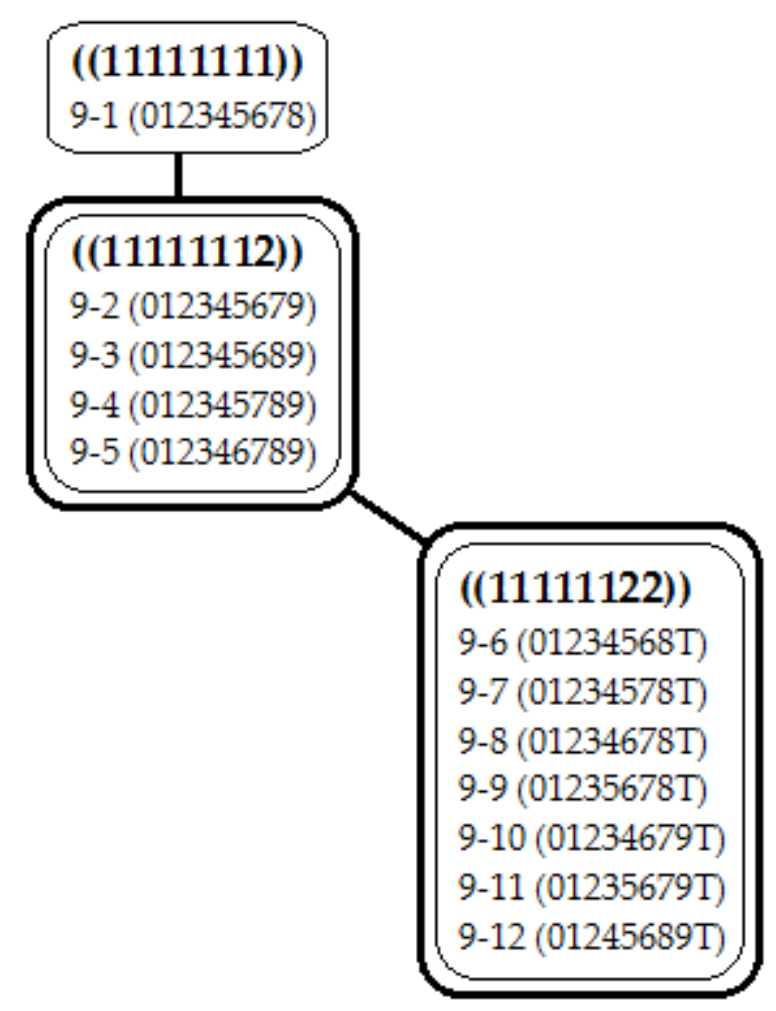

Figure 15: Voice-leading space for sets of cardinality 9 based on PCORDs

Among the musical examples we analyzed in this study, the most interesting from the point of view of parsimony trajectory is Example 2 of VillaLobos' Rudepoema. The trajectories of the others examples stay inside one box of the same PCORD. Figure 16 shows the five-step trajectory moving between different set classes of PCORDs $((1223))$ and ((1223)) that characterize this progression.

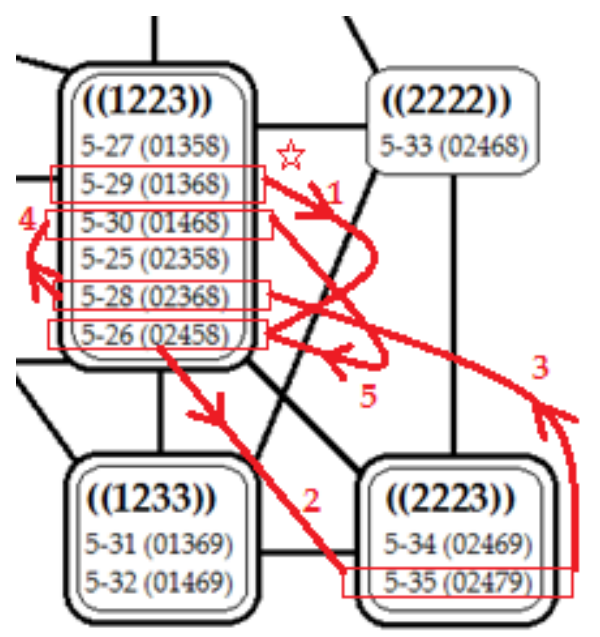

Figure 16: Five-step trajectory of Example 2 (excerpt of Villa-Lobos' Rudepoema) 


\section{PCORD and harmonic perception}

As it happens many times with theories that employ Forte's set classes, this also has received remarks on its relation to perception whenever it was presented, yet incomplete. Is it possible to listen to PCORD relations? Perhaps it is impossible to listen even to pitch set classes, isn't it? What about interval set classes? My answer is: perception has many levels. PCORD perception should be concerned with qualities derived from wave interferences, beating, roughness, and other psychoacoustic phenomena. Therefore, it is indeed possible to listen to PCORD-relations, but in a quite different way than listening to actual pitches: listening to the qualities of sound complexes.

Misunderstandings about theories can occasionally lead to new theories. Perle (1990, p. 7) already made this point eloquently. In the 70's, I was studying composition with Claudio Santoro who showed me how to use elements of pitchset manipulation. His practice was rooted in classical serial and twelve-tone theory. He mentioned that set theory was a new important trend in the USA. However, we did not have access, at that time, to the literature on the subject and I started to guess what would be that theory about. As the state of the art knowledge on serial music was about pitch-classes, I thought that this new theory should be about the intervals, in a higher structural level.

In mid-80's, my compositional practice became committed to a systematic search of computer generated models of intervals reordering. As often happens, the practice predated the theory, so my PCORD theory only came decades later.

The origin of Forte's set theory was the IBM challenge of using the computer for music analytical purposes (Schuijer 2011, p. 236). Soon, Morris (1979) proposed that set theory might be used to support new compositional practices in atonal music. In sequence, the combination of set theory with algorithmic tools, to develop the field of computer aided-composition, was a natural step forward, which many composers tried. As Gerhard Nierhaus (2010) demonstrates, the field of algorithm composition, eventually using set theory, continues up today to unfold new ideas, generating new compositional strategies and theoretical reflection. What follows is one of those strategies.

The special nature of trichords can be verified on item 6, which presents tables of the relation between PCORDs and Set- Classes. We already pointed out that, with respect to PCORD, trichords are unique. A trichord does not have a $\mathrm{Z}$ or PCORD structural relation with any other trichord. Parks remind us that, in 
his essay of 1988, Forte "identified twelve genera by means of inclusion relations focused about trichords" (Parks 1998, p. 206). Therefore, our observation reinforces Forte's set genera building block premise.

There are 12 trichords. They identify fundamental sonorities like $\mathrm{M} / \mathrm{m}$ chords, diminished or augmented chords, as the most often mentioned, but all twelve species of trichords have harmonically significant individualities. Maybe this starting point has inspired Forte to classify set genera also in 12 categories.

There is no point of proposing a new theory of set genera, or to modify Forte's and Parks' theories. My proposition aims just the compositional practice.

The idea is that we may analyze any set or set class of higher cardinality with trichords (or PCORDs of cardinality 3), producing a vector of trichord harmonic content for each set class, similarly to what has been done with the interval vector.

Take, for instance, the set $\{C, D, E b, G b, B\}$ that belongs to set class 5-25 (02358). The number of trichords that can be generated by these pitches is the combinatorial:

$\left({ }^{\mathrm{n}} \mathrm{r}\right)=\left({ }^{5}{ }_{3}\right)=\mathrm{n} ! /[\mathrm{r} !(\mathrm{n}-\mathrm{r}) !]=5 ! /(3 ! .2 !)=10$

Arranging permutations and calculating their set classes, we may find their respective PCORDs:
$\mathrm{C}, \mathrm{D} b, \mathrm{E} b \quad \rightarrow((12))$
$\mathrm{C}, \mathrm{D}, \mathrm{G}, \quad \rightarrow((15))$
$\mathrm{C}, \mathrm{D}, \mathrm{B}, \quad \rightarrow((12))$
$\mathrm{C}, \mathrm{E} b, \mathrm{G} b \quad \rightarrow((33))$
$\mathrm{C}, \mathrm{E} b, \mathrm{~B}, \quad \rightarrow((23))$
$\mathrm{C}, \mathrm{G}, \mathrm{E}, \mathrm{E} \quad \rightarrow((24))$
$\mathrm{D} b, \mathrm{E} b, \mathrm{G} b \quad \rightarrow((23))$
$\mathrm{D} b, \mathrm{E} b, \mathrm{~B}, \quad \rightarrow((23))$
$\mathrm{D}, \mathrm{G}, \mathrm{B}, \quad \rightarrow((34))$
$\mathrm{E} b, \mathrm{G} b, \mathrm{~B}, \quad \rightarrow((34))$

Arranging the trichord content of that set of cardinality 5 using PCORD representation, we have the vector displayed in Figure 17.

\begin{tabular}{|c|c|c|c|c|c|c|c|c|c|c|c|}
\hline$((11))$ & $((12))$ & $((13))$ & $((14))$ & $((15))$ & $((22))$ & $((23))$ & $((24))$ & $((25))$ & $((33))$ & $((34))$ & $((44))$ \\
\hline 0 & 2 & 0 & 0 & 1 & 0 & 3 & 1 & 0 & 1 & 2 & 0 \\
\hline
\end{tabular}

Figure 17: PCORD-3 vector of set class 5-25 (02358)

We can apply a PCORD-3 analysis to the most commonly mentioned referential collections in influential books like Tymoczko (2011) and Straus 
MUSICA THEORICA Revista da Associação Brasileira de Teoria e Análise Musical 2018, v. 3, n. 2, p. 46-85 - Journal of the Brazilian Society for Music Theory and Analysis @ TeMA 2018 - ISSN 2525-5541

(2016), which basically coincides with Parks' genera. Figure 18 displays the result of this task.

\begin{tabular}{|l|c|c|c|c|c|c|c|c|c|c|c|c|}
\hline Type & Chro & Oct & $\begin{array}{l}\text { Hex } \\
\text { Oct }\end{array}$ & Hex & Aton & WT & $\begin{array}{l}4 \text { ths } \\
\text { Oct }\end{array}$ & $\begin{array}{l}\text { WT } \\
\text { Oct }\end{array}$ & 4 ths & Dim & M/m & Aum \\
\hline \multicolumn{1}{|c}{ PCORD } & $((11))$ & $((12))$ & $((13))$ & $((14))$ & $((15))$ & $((22))$ & $((23))$ & $((24))$ & $((25))$ & $((33))$ & $((34))$ & $((44))$ \\
\hline Pentatonic & - & - & - & - & - & 1 & $\mathbf{4}$ & - & $\mathbf{3}$ & - & 2 & - \\
\hline Diatonic & - & 4 & - & 4 & 2 & 3 & $\mathbf{8}$ & 2 & $\mathbf{5}$ & 1 & $\mathbf{6}$ & - \\
\hline Acoustic & - & $\mathbf{4}$ & 2 & 2 & 2 & 3 & $\mathbf{6}$ & $\mathbf{6}$ & 3 & 2 & $\mathbf{4}$ & 1 \\
\hline WholeTone & - & - & - & - & - & $\mathbf{6}$ & - & $\mathbf{1 2}$ & - & - & - & $\mathbf{4}$ \\
\hline Octatonic & - & $\mathbf{8}$ & $\mathbf{8}$ & - & $\mathbf{8}$ & - & $\mathbf{8}$ & $\mathbf{8}$ & - & $\mathbf{8}$ & $\mathbf{8}$ & - \\
\hline Hexatonic & - & - & $\mathbf{6}$ & $\mathbf{6}$ & - & - & - & - & - & - & $\mathbf{6}$ & 2 \\
\hline
\end{tabular}

Figure 18: PCORD-3 vectors of the main referential collections

After we counted the frequency of each PCORD-3, for each paradigmatic collection, we verified that (as expected) some trichords are characteristic of certain collections. For instance, the Octatonic has 8 diminished triads, 8 Major/minor triads and 8 atonal triads or (016). Straus (2016, p. 378$)$ assigned the label "octatonic segment"" to the trichord ((12)), but we thought it was fair to assign the same label "oct" to equally prominent triads as ((23)), ((12)) and ((24)) that had not received any label from him. The same happens with the WholeTone collection, where $((22))$ and $((24))$ are relevant but Straus had labeled as "whole-tone segment" only the first one; and with the Hexatonic where Straus labeled "hexatonic segment" the ((13)) but not the ((14)). The Pentatonic, also, allows us to recognize both $((23))$ and $((24))$ as significant stacks of fourths or quartal chords. The Diatonic and the Acoustic do not yield any trichord label because the most relevant trichords for them are the well know $\mathrm{M} / \mathrm{m}$ and quartal chords. However, their comparison gives us some quite interesting results. We can realize that they share less than $30 \%$ of their trichord content. This table can also help us to design harmonic strategies. For instance, the trichord after ((24)) can be used to modulate to the whole-tone collection easier from the acoustic than from the diatonic, but nor from the pentatonic neither the hexatonic.

As a final note on the topic of paradigmatic collections, we may recall that Tymoczko (2011, p. 126) includes among them, two collections he calls the "harmonic minor" and the "harmonic major". Our analysis has shown that the trichord content of both is the same and that they have a high dispersion of 
trichord types, ${ }^{9}$ making them quite less useful for our taxonomic purpose. Therefore, we decided to leave them out of the chart.

The analysis of trichord vectors of sets of higher cardinality is, ultimately, equivalent to a study of subsets. Notwithstanding it can be a practical device to help compositional choices and analytical insights. Figure 19 presents a table of PCORD-3 vectors of all cardinality 4 set classes, identifying also the labels usually attached to these collections.

\begin{tabular}{|c|c|c|c|c|c|c|c|c|c|c|c|c|c|}
\hline & Type & Chro & Oct & $\begin{array}{l}\text { Hex } \\
\text { Oct }\end{array}$ & Hex & Aton & WT & $\begin{array}{l}\text { 4ths } \\
\text { Oct }\end{array}$ & $\begin{array}{l}\text { WT } \\
\text { Oct }\end{array}$ & Aths & Dim & $\mathrm{M} / \mathrm{m}$ & Aum \\
\hline$\overline{\mathrm{PCO}} \overline{\mathrm{R}} \mathrm{B}$ & & ((ii)) & (ii2) & (13)) & ((10)) & (15) & $(\overline{2 i 2}))$ & (i23)) & (i2i) & (i(25)) & (43)) & ((34) & (i(6)i) \\
\hline ((111)) & $\begin{array}{l}(0123) 4-1 \\
x \text {-cell }\end{array}$ & 2 & 2 & - & - & - & - & - & - & - & - & - & - \\
\hline \multirow[t]{2}{*}{$((112))$} & $(0124) 4-2$ & 1 & 1 & 1 & - & - & 1 & - & - & - & - & - & - \\
\hline & $\begin{array}{l}\text { (0134) } 4-3 \\
\text { Octat, seg. }\end{array}$ & - & 2 & 2 & 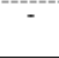 & - & $=$ & - & 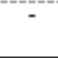 & - & 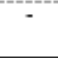 & - & - \\
\hline \multirow[t]{2}{*}{$((113))$} & $(0125) 4-4$ & 1 & - & 1 & 1 & - & - & 1 & - & - & - & - & - \\
\hline & $\begin{array}{l}(0145) 4-7 \\
\text { Hexat, seg. }\end{array}$ & - & - & 2 & 2 & 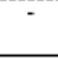 & - & - & - & - & - & - & - \\
\hline \multirow[t]{2}{*}{ ((122)) } & (0135) 4-11 & - & 1 & - & 1 & - & 1 & 1 & - & - & - & - & - \\
\hline & $\begin{array}{l}(0235) \text { 4-10 } \\
\text { Octat. seg. }\end{array}$ & - & 2 & - & $"$ & - & - & 2 & - & - & - & - & - \\
\hline \multirow[t]{2}{*}{ ((114)) } & $(0126) 4-5$ & 1 & - & - & 1 & 1 & - & - & 1 & - & - & - & - \\
\hline & (0156) 4-8 & $=$ & - & - & 2 & 2 & - & - & - & - & - & - & $=$ \\
\hline \multirow[t]{3}{*}{ ((123)) } & $(0136) 4-13$ & - & 1 & - & - & 1 & - & 1 & - & - & 1 & - & - \\
\hline & $\begin{array}{l}(0146) 4-15 \\
\text { All interv. }\end{array}$ & - & - & 1 & - & 1 & - & 1 & 1 & - & - & - & - \\
\hline & $\begin{array}{l}\text { (0236) 4-12 } \\
\text { Octat. seg. }\end{array}$ & - & 1 & 1 & - & - & - & - & 1 & - & 1 & - & - \\
\hline$(((222)))$ & $\begin{array}{l}\text { (0246) 4-21 } \\
\text { WT, y-cell }\end{array}$ & - & - & - & - & - & 2 & - & 2 & - & - & - & - \\
\hline \multirow[t]{2}{*}{$((115))$} & $(0127) 4-6$ & 1 & - & - & - & 2 & - & - & - & 1 & - & - & - \\
\hline & $\begin{array}{l}(0167) 4-9 \\
x \text {-cell }\end{array}$ & $=$ & 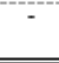 & $=$ & - & 4 & $=$ & - & 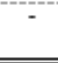 & - & 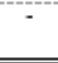 & - & \\
\hline \multirow[t]{3}{*}{$(((124)))$} & $\begin{array}{l}\text { (0137) 4-29 } \\
\text { All interval }\end{array}$ & - & 1 & - & - & 1 & - & - & 1 & - & - & 1 & - \\
\hline & (0237) 4-14 & $=$ & 1 & $=$ & 1 & - & $=$ & - & $=$ & 1 & $=$ & 1 & - \\
\hline & $(0157) 4-16$ & - & - & - & 1 & 1 & - & - & 1 & 1 & - & - & - \\
\hline \multirow[t]{2}{*}{$((133))$} & $(0147)$ 4-18 & - & - & 1 & $=$ & 1 & - & - & - & $=$ & 1 & 1 & - \\
\hline & $\begin{array}{l}(0345) 4-17 \\
\mathrm{M} / \mathrm{m}\end{array}$ & - & - & 2 & - & - & - & - & - & - & - & 2 & - \\
\hline \multirow[t]{2}{*}{$((223))$} & $\begin{array}{l}(0245) 4-22 \\
\text { Fourths }\end{array}$ & - & - & - & - & - & 1 & 1 & - & 1 & - & 1 & - \\
\hline & $\begin{array}{l}(0257) 4-23 \\
\text { Fourths }\end{array}$ & - & - & - & - & - & - & 2 & - & 2 & - & - & - \\
\hline \multirow[t]{2}{*}{$((134))$} & (0148) 4-19 & $\therefore$ & - & 1 & 1 & - & - & - & $=$ & $=$ & - & 1 & 1 \\
\hline & (0158) 4-20 & $=$ & - & $=$ & 2 & $=$ & $=$ & - & - & $=$ & - & 2 & - \\
\hline \multirow[t]{2}{*}{$((224))$} & $\begin{array}{l}\text { (0248) 4-24 } \\
\text { whole-tone }\end{array}$ & - & - & - & - & - & 1 & - & 2 & - & - & - & 1 \\
\hline & $\begin{array}{l}(0268) 4-25 \\
\text { French } 6+\end{array}$ & - & 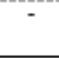 & - & 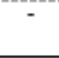 & - & 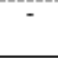 & - & 4 & - & - & - & 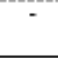 \\
\hline \multirow[t]{2}{*}{$((233))$} & $\begin{array}{l}(0358) 4-26 \\
\mathrm{~m} 7\end{array}$ & - & - & - & - & - & - & 2 & - & - & - & 2 & - \\
\hline & $\begin{array}{l}(0258) 4-27 \\
\text { Half.dim } 7^{\text {th }}\end{array}$ & - & - & - & - & 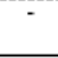 & - & 1 & 1 & - & 1 & 1 & - \\
\hline$(((333)))$ & $\begin{array}{l}(0369) 4-28 \\
\operatorname{dim} 7^{2}\end{array}$ & - & - & - & - & - & - & - & - & - & 4 & - & - \\
\hline
\end{tabular}

Figure 19: PCORD-3 vectors of cardinality 4 set classes

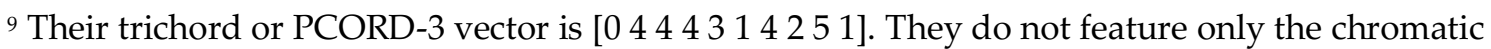
cluster (011).
} 
MUSICA THEORICA Revista da Associação Brasileira de Teoria e Análise Musical 2018, v. 3, n. 2, p. 46-85 - Journal of the Brazilian Society for Music Theory and Analysis @ TeMA 2018 - ISSN 2525-5541

The art of composition with set classes can be compared with the creation of a perfume. Each set class has an identity based on basic components that we may relate to their triadic internal relations. We may juxtapose or mix set classes based on the harmonic affinities according to the content presented by their PCORD-3 vectors.

As we did for set classes of cardinality 4, Figure 20 presents the PCORD-3 vectors for all set classes of cardinality 5 .

\begin{tabular}{|c|c|c|c|c|c|c|c|c|c|c|c|c|c|}
\hline & $\begin{array}{r}\text { Type } \\
\text { Set-Class }\end{array}$ & Chro & Oct & $\begin{array}{l}\text { Hex } \\
\text { Oct }\end{array}$ & Hex & Aton & WT & $\begin{array}{l}\text { 4ths } \\
\text { Oct }\end{array}$ & $\begin{array}{l}\text { WT } \\
\text { Oct }\end{array}$ & 4ths & Dim & $\mathrm{M} / \mathrm{m}$ & Aum \\
\hline PCORD & & ((11)) & ((12)) & ((13)) & ((14)) & (15)) & $((22))$ & ((23)) & $((24))$ & $((25))$ & ((33)) & ((34)) & ((44)) \\
\hline ((1111)) & (01234) 5:1 & 3 & 4 & 2 & - & - & 1 & - & - & - & - & - & - \\
\hline \multirow[t]{2}{*}{$((\mathbf{1 1 1 2 ) )}$} & $(01235) 5-2$ & 2 & 3 & 1 & 1 & $\therefore$ & 1 & 2 & $=$ & $=$ & - & - & $=$ \\
\hline & (01245) $5 \cdot 3$ & 1 & 2 & 3 & 2 & - & 1 & 1 & - & - & - & - & - \\
\hline \multirow[t]{2}{*}{ ((1113)) } & $(01236) 5-4$ & 2 & 2 & 1 & 1 & 1 & $=$ & 1 & 1 & - & 1 & - & - \\
\hline & (01256) 5.6 & - & 1 & 3 & 2 & 2 & $=$ & 1 & 1 & $=$ & $=$ & $=$ & $=$ \\
\hline \multirow[t]{4}{*}{$((1122))$} & (01246) 5-9 & $\overline{11}$ & $\overline{1}$ & $\overline{1}$ & 1 & $\overline{1}$ & $\overline{1} 1$ & $\overline{1}$ & $\overline{2}$ & - & 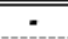 & 1 & - \\
\hline & $(01346) 5-10$ & $=$ & 3 & 2 & $=$ & 1 & 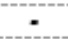 & 2 & 1 & - & 1 & - & - \\
\hline & $(01356) 5-12$ & $=$ & 2 & - & 2 & 2 & 1 & 2 & $=$ & $=$ & 1 & $=$ & $=$ \\
\hline & $(02346) 5 \cdot 8$ & 1 & 2 & 2 & - & - & 2 & $=$ & 2 & - & 1 & - & $\because$ \\
\hline \multirow[t]{2}{*}{$((1114))$} & $(01237) 5-5$ & 1 & 3 & - & 1 & 2 & - & $=$ & 1 & 1 & - & 1 & - \\
\hline & (01267) 5-7 & - & 1 & - & 2 & 5 & - & - & 1 & 1 & - & - & - \\
\hline \multirow[t]{6}{*}{$((1123))$} & $(01247) 5-36$ & $=$ & 2 & 1 & - & 2 & 1 & 1 & 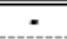 & 1 & 1 & 1 & - \\
\hline & $(01257) 5-14$ & - & 1 & 1 & 1 & 2 & - & 2 & 1 & 2 & $=$ & $=$ & - \\
\hline & $(01347) 5-16$ & - & 2 & 3 & - & 1 & $=$ & - & 1 & $=$ & 1 & 2 & - \\
\hline & $(01367) 5-19$ & - & 1 & 1 & - & 4 & - & 1 & 1 & - & 1 & 1 & - \\
\hline & $(01457) 5-18$ & - & 1 & 2 & 2 & 1 & $=$ & $=$ & 1 & 1 & 1 & 1 & - \\
\hline & $(02347) 5-11$ & 1 & 1 & 2 & 1 & - & 1 & 1 & - & 1 & - & 2 & - \\
\hline \multirow[t]{2}{*}{$((1222))$} & $(01357) 5-24$ & $=$ & 1 & - & 1 & 1 & 2 & 1 & 2 & 1 & - & 1 & 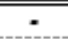 \\
\hline & $(02357) 5-23$ & - & 2 & 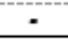 & 1 & - & 1 & 3 & - & 2 & - & 1 & - \\
\hline \multirow[t]{4}{*}{$((1124))$} & $(01248) 5-13$ & 1 & 2 & $\therefore$ & 1 & 1 & 1 & - & 2 & - & - & 1 & 1 \\
\hline & $(01268) 5-15$ & 1 & - & - & 2 & 2 & - & - & 4 & 1 & $=$ & - & - \\
\hline & $(01348) 5-17$ & $=$ & 2 & 2 & 2 & - & - & $=$ & - & 1 & - & 2 & 1 \\
\hline & $(01568) 5-20$ & - & 1 & - & 3 & 2 & - & - & 1 & 1 & - & 2 & - \\
\hline \multirow[t]{4}{*}{$((1133))$} & $(01258) 5-38$ & $=$ & 1 & 1 & 2 & 1 & - & 1 & 1 & - & 1 & 2 & - \\
\hline & $(01458) 5-21$ & $=$ & - & 3 & 3 & - & - & - & - & - & - & 3 & 1 \\
\hline & $(01478) 5-22$ & - & - & 2 & 2 & 2 & - & - & - & - & 1 & 2 & 1 \\
\hline & $(03458) 5-37$ & 1 & - & 2 & 2 & - & - & 2 & - & - & - & 2 & 1 \\
\hline \multirow[t]{6}{*}{$((1223))$} & (01358)5-27 & 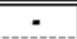 & 1 & - & 2 & 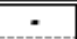 & 1 & 2 & - & 1 & $=$ & 3 & - \\
\hline & $(01368) 5-29$ & - & 1 & - & 1 & 1 & $=$ & 2 & 1 & 2 & 1 & 1 & - \\
\hline & $(01468) 5-30$ & - & - & 1 & 1 & 1 & 1 & 1 & 2 & 1 & - & 1 & 1 \\
\hline & $(02358) 5-25$ & - & 2 & - & - & 1 & - & 3 & 1 & $=$ & 1 & 2 & \\
\hline & $(02368) 5-28$ & $=$ & 1 & 1 & $=$ & 1 & - & 1 & 4 & - & 1 & 1 & - \\
\hline & $(02458) 5-26$ & $=$ & 1 & 1 & 1 & $=$ & 1 & 1 & 2 & 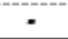 & 1 & 1 & 1 \\
\hline$((2222))$ & (02468)5-33 & - & - & - & - & - & 3 & - & 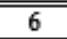 & - & 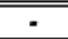 & - & 1 \\
\hline \multirow[t]{2}{*}{$((1233))$} & (01369)5-31 & $=$ & $\overline{1}$ & $\overline{1 .}$ & $=$ & 1 & $=$ & 1 & 1 & $=$ & 4 & 1 & 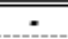 \\
\hline & (01469)5-32 & - & - & 2 & - & 1 & - & 2 & 1 & - & 1 & 3 & - \\
\hline \multirow[t]{2}{*}{$((2223))$} & (02469)5-34 & - & - & - & - & - & 2 & 2 & 2 & 1 & 1 & 2 & - \\
\hline & $(02479) 5-35$ & 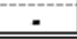 & - & $=$ & $=$ & - & 1 & 4 & $=$ & 3 & $=$ & 2 & 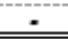 \\
\hline
\end{tabular}

Figure 20: PCORD-3 vectors of cardinality 5 set classes

We will leave the study of set classes of Cardinalities 6, 7, 8 and 9 with PCORD-3 vectors for another paper, because the complexity of the problem might lead us too far away. 


\section{Using PCORD as a compositional tool}

This section could be endless, depending on our imagination. We will provide only one example to illustrate our proposition.

Take, for instance, the following problem: we want to rewrite the progression of Hans Otte's music of Example 3 with pitch-class sets of cardinality 5 figuring out a pathway from a set containing some major/minor trichords, passing by a whole-tone y-cell (0246) and finishing with a set containing a z-cell (0167), a familiar procedure in Bartók's music.

We can start with 5-34 (02469) e go to 5-33 (02468) which, according to the table of Figure 13, has the largest number of whole-tone characteristic trichords: 6 of $((22))$ and 4 of $((24))$. Our goal is to reach 5-7 (01267), which, according to table 13 , has 5 instances of $((15))$, the characteristic trichords of the z-cell 5-31 (01369) that has 4 instances of ((15)).

These sets have only one trichord in common. We may want one or more intermediary set classes with a larger trichord common ground to make the transition smoother. The best candidates, according to table 13 are 5-Z36 (01247), 5-12 (01356) and 5-24 (01357) that have three trichords in common, instead of one.

We may also want to maximize common tones and go through the smoothest chromatic voice leading. Consulting the table of Figure 6, we may choose the following pathway:

$5-34(02469) \rightarrow 5-33(02468) \rightarrow 5-23(02357) \rightarrow 5-24(01357) \rightarrow 5-16(01347)$

$\rightarrow$ 5-Z36 (01247) $\rightarrow$ 5-14 (01257) $\rightarrow$ 5-7 (01267)

Implementing the progression with pitch-classes:
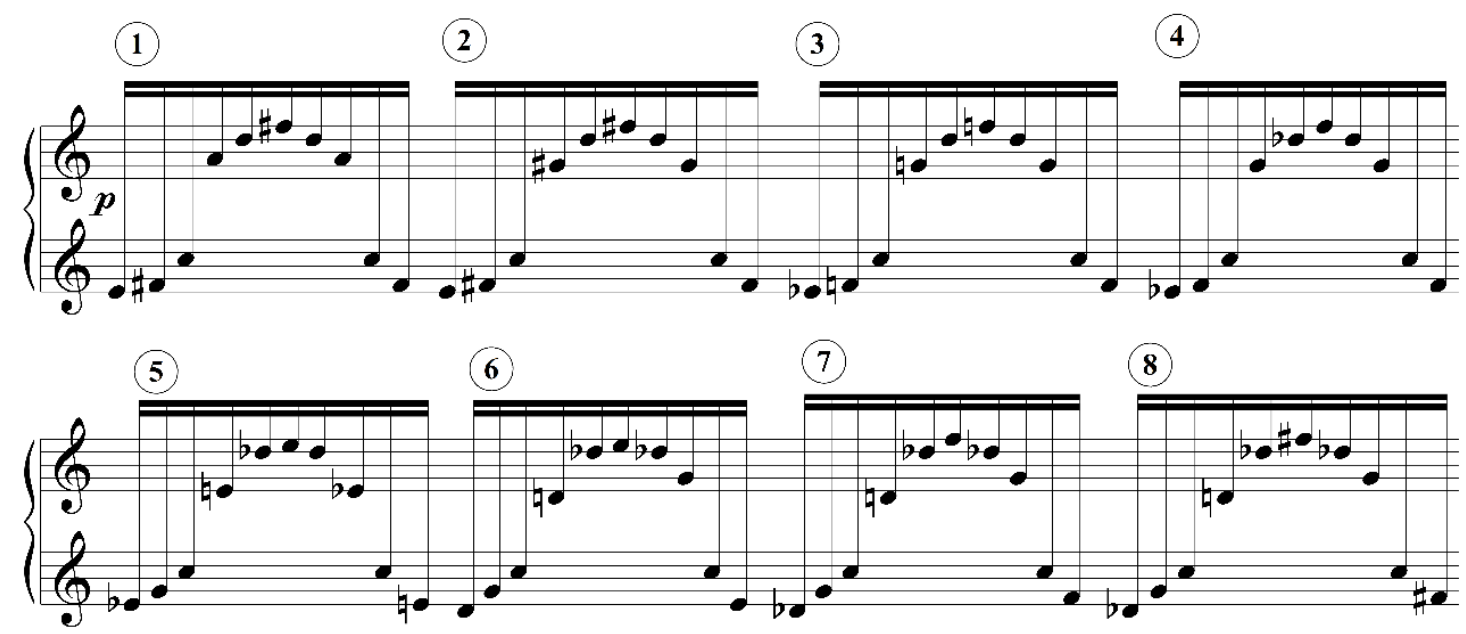
MUSICA THEORICA Revista da Associação Brasileira de Teoria e Análise Musical 2018, v. 3, n. 2, p. 46-85 - Journal of the Brazilian Society for Music Theory and Analysis @ TeMA 2018 - ISSN 2525-5541

\begin{tabular}{|c|c|c|c|}
\hline & Pitches & Set-Class & PCORD \\
\hline 1 & E , C, F\#, A, D & $5-34(02469)$ & $((2223))$ \\
\hline 2 & E, C, F\#, G\#, D & $5-33(02468)$ & $((222))$ \\
\hline 3 & Eb, C, F, G, D & $5-23(02357)$ & $((1222))$ \\
\hline 4 & Eb, C, F, G, Db & $5-24(01357)$ & $((1222))$ \\
\hline 5 & Eb, C, E, G, Db & $5-16(01347)$ & $((1223))$ \\
\hline 6 & D, C, E, G, Db & $5-Z 36(01247)$ & $((1223))$ \\
\hline 7 & D, C, F, G, Db & $5-14(01257)$ & $((1223))$ \\
\hline 8 & D, C, F\#, G, Db & $5-7(01267)$ & $((1114))$ \\
\hline
\end{tabular}

Example 6: Rewriting Hans Otte's Das Buch der Klänge 2

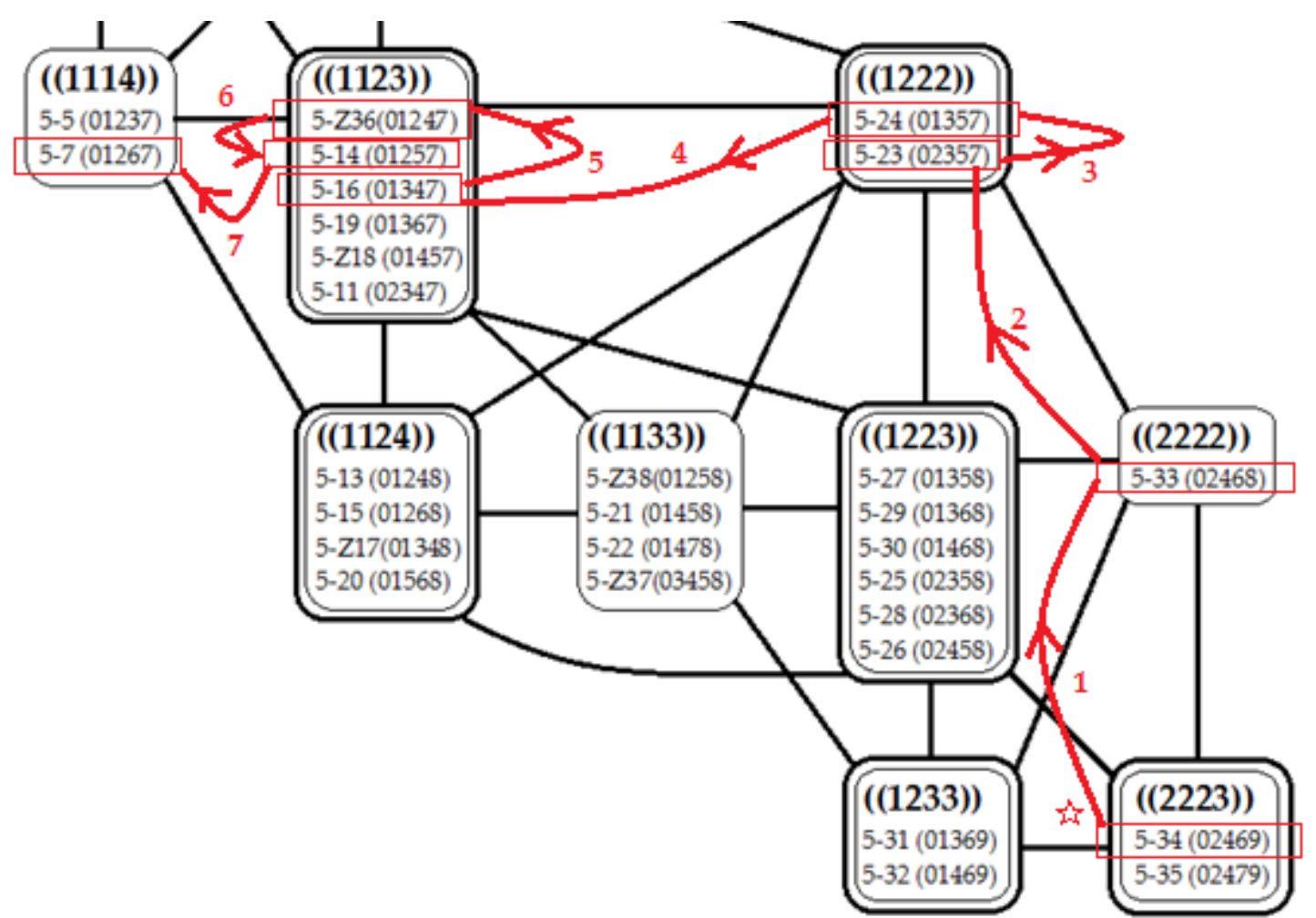

Figure 21: Seven-step trajectory of the rewritten excerpt of Example 6 


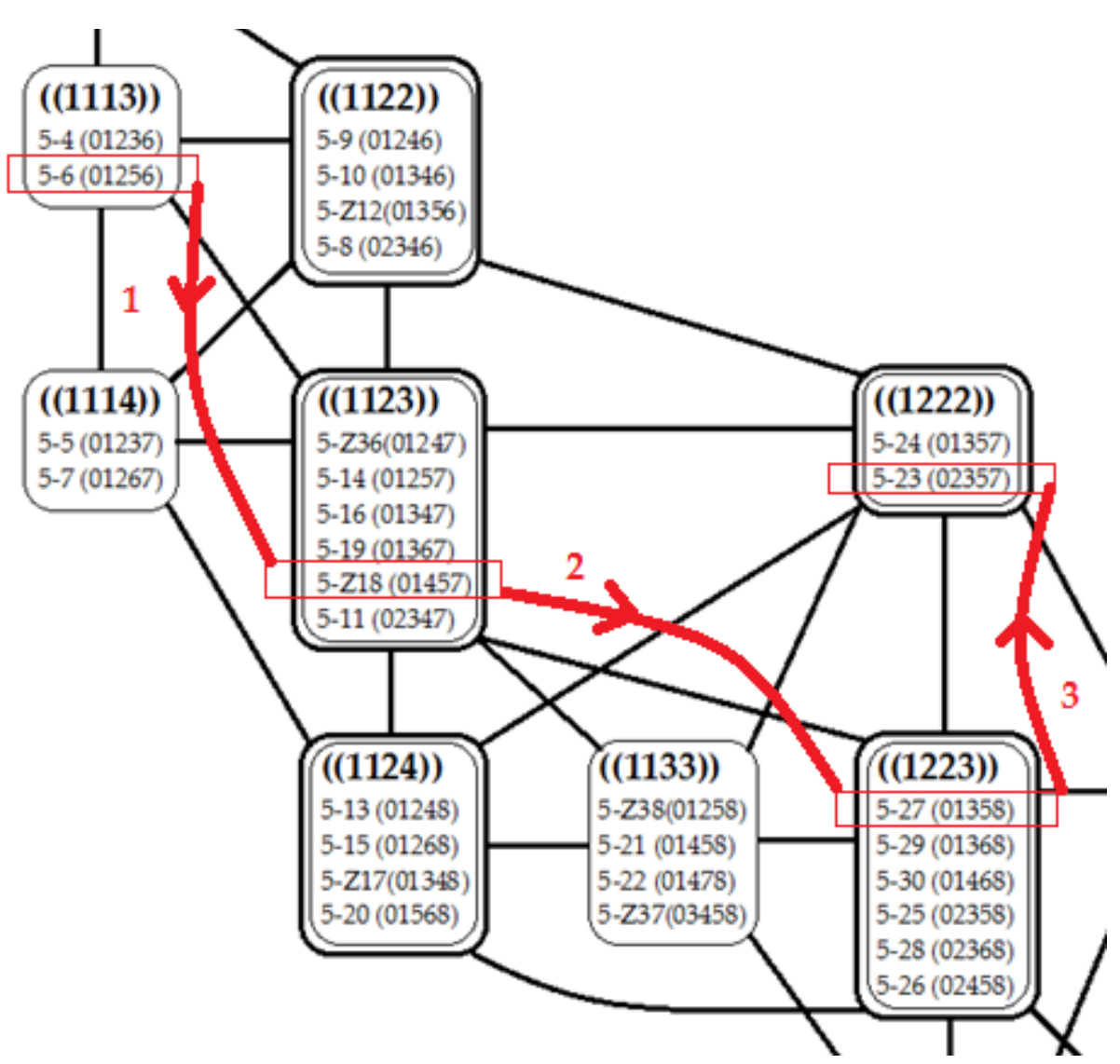

Figure 22: Three-step trajectory of the Santoro's excerpt of Example 1

Straus observes that for set classes voice-leading spaces, "in general, the harmonies that are traditionally considered more tense and dissonant are found toward one end of the spaces, while the harmonies traditionally considered more relaxed and consonant are found toward the other" (Straus 2016, p. 183). Figure 14 shows that something very similar happens for voice-leading spaces designed with PCORD. Our trajectory started with pentachords with strong content of consonant triads and finished with the pentachord with the most dissonant atonal content, sometimes stalling in the middle in groups of half-dissonant sets. However, in this context, the idea of tension and relaxation is a bad metaphor, perhaps. The light spectrum is a better one, with its diversity of qualities, which we see as colors, dispersed throughout the frequency pallet.

Could this different point of view fix our previous understanding of the apparently meaningless analytical result of Example 1 (Santoro's piece)? Figure 15 shows that trajectory between set classes of the excerpt seems to have some sense, going from a more dissonant to a more consonant set, with smooth abstract voice-leading in the set class space. However, this excerpt is too short to allow some conclusion about the syntax of the piece in this aspect. Moreover, pieces in 
twelve-tone style tend to be harmonically static as they fill quite fast the aggregate. The same tendency to harmonic stasis is expected in pieces of minimalistic style. Our Examples 2-3-4-5 confirm this hypothesis. However, there are atonal styles that use dynamic harmonic progressions. This study intends to offer a tool for the composer and the analyst to deal, in atonal music, with the directionality of harmonic progressions.

\section{Conclusions}

This research demonstrates that, if the focus on pitch-class sets were the initial path of Forte's Set Theory and produced, among many other things, a useful taxonomy of set classes, on the other hand, other interesting findings may result if we shift our focus from pitches to intervals and from objects to relations. David Lewin's GIS - Generalized Interval System pointed in that direction.

In this perspective, the coincidence of the prime form of the interval string (or PCORD) of different set classes allows a structural relation that can provide a link between them, granting a level of organic coherence to certain compositions of post-tonal music. We tried to demonstrate the potential of this hypothesis providing some analytical examples, including compositions of the author of the article who had considered this property as a promising departing point for his computer aided-composition.

This compositional practice also proved the fundamental role of voice leading for the successful manipulation of expanded set classes relations, both in literal and abstract procedures. This leads to the study of the parsimony between set classes related by PCORD. The tables of PCORD voice-leading spaces provided in this essay intend to help the design of pre-compositional strategies and the decision process.

On the other hand, the table of PCORDs $x$ Set classes had revealed that each set class of cardinality 3 has a unique PCORD, as if they were elementary DNA components of larger sets. This confirms Forte's and Parks' assumption that trichords could be a proper fundament for a Set Genera Theory. Nevertheless, neither of these authors produced a thorough analysis of the harmonic characteristics of each set class, taking into consideration trichords and paradigmatic collections. The tables provided here can also help to enhance the training of post-tonal music perception. These tables, in conjunction with the voice-leading space based on PCORD, may constitute a useful tool for pre- 
compositional design, allowing the composer to control the quality of harmonic dissonance in atonal progressions.

\section{References}

1. Cervo, Dimitri. 2005. O minimalismo e sua influência na composição musical brasileira contemporânea. Santa Maria: Editora UFSM.

2. Coelho de Souza, Rodolfo. 2012. Uma nova relação de Forte aplicada à música brasileira pós-tonal. In: Maria Alice Volpe (Org.) Teoria, crítica e música na atualidade, Vol. 2. Rio de Janeiro: Editora da UFRJ, p. 211-222.

3. Eimert, Herbert. 1961. Debussy's Jeux. Die Reihe 5: 3-20.

4. Forte, Allen. 1964. A Theory for Set-Complexes for Music. Journal of Music Theory 8/2, p. 136-183.

5. _ـ 1973. The Structure of Atonal Music. New Haven: Yale University Press.

6. 1 1988. Pitch-Class Set Genera and the Origin of Modern Harmonic Species. Journal of Music Theory 32/2, p. 187-270.

7. Hanninen, Dora. 2012. A Theory of Music Analysis: On Segmentation and Associative Organization. Rochester: University of Rochester Press.

8. Hanson, Howard. 1960. The Harmonic Materials of Twentieth-Century Music. New York: Appleton-Century-Crofts.

9. Isaacson, Eric. 1990. Similarity of Interval-Class Content between Pitch-Class Sets: The IcVSIM Relation. Journal of Music Theory, 34/1, p. 1-28.

10. Lewin, David. 1959. Re: Intervallic Relations Between Two Collections of Notes. Journal of Music Theory 3, p. 298-301.

11. _ 1960. Re: The Intervallic Content of a Collection of Notes and Its Complement: An Application to Schoenberg's Hexachordal Pieces. Journal of Music Theory 4, p. 98-101.

12. _. 1977. Forte's 'Interval Vector, My Interval Function', and Regener's 'Common-Note Function'. Journal of Music Theory, 21/2, p. 194-237.

13. _ (1979). A Response to a Response: On Pcset Relatedness. Perspectives of New Music 18, p. 498-502.

14. Larsen, Juliane. 2011. O uso motívico de uma série em uma obra dodecafônica de Cláudio Santoro. In: Anais do XXI Congresso da Anppom, p. 1801-06.

15. Lord, Charles. 1981. Intervallic Similarity Relations in Atonal Set Analysis. Journal of Music Theory 25, p. 91-111. 
MUSICA THEORICA Revista da Associação Brasileira de Teoria e Análise Musical 2018, v. 3, n. 2, p. 46-85 - Journal of the Brazilian Society for Music Theory and Analysis @ TeMA 2018 - ISSN 2525-5541

16. Morris, Robert D. 1979. A Similarity Index for Pitch-Class Sets. Perspectives of New Music 18, p. 445-60.

17. _ 1987. Composition with Pitch-Classes: A Theory of Compositional Design. New Haven: Yale University Press.

18. Nierhaus, Gerhard. 2010. Algorithm Composition. Wien: Springer.

19. Oliveira, João Pedro P. 1998. Teoria Analítica da Música do Século XX. Lisboa: Gulbenkian.

20. Perle, George. 1990. The Listening Composer. Berkeley: University of California Press.

21. Parks, Richard S. 1989. The Music of Claude Debussy. New Haven: Yale University Press.

22. _ 1998. Pitch-Class Set Genera: My Theory, Forte's Theory. Music Analysis 17/2, p. 206-226.

23. Rahn, John. 1979. Relating Sets. Perspectives of New Music 18, p. 483-98.

24. Schuijer, Michiel. 2008. Analyzing Atonal Music: Pitch-Class Set Theory and Its Contexts. Rochester: University of Rochester Press.

25. Soderberg, Stephen. 1995. "Z-Related Sets as Dual Inversions." Journal of Music Theory 39/1, p. 77-100

26. . 1998. “The T-Hex Constellation." Journal of Music Theory 42/2. p. 207218.

27. Straus, Joseph N. 2016. Introduction to Post-Tonal Theory (4th ed.). New York: W. W. Norton.

28. Tymoczko, Dmitri. 2011. A Geometry of Music: Harmony and Counterpoint in the Extended Common Practice. Oxford: Oxford University Press. 